2. BIBLIOGRAFÍA Y PRENSA

2. Bibliography and press

\title{
UNA DÉCADA DE PUBLICACIONES SOBRE HISTORIA DE LA EDUCACIÓN DE LAS MUJERES (2007-2017)
}

\section{A decade of publications on the History of Women's Education (2007-2017)}

Consuelo Flecha García

Universidad de Sevilla

Correo-e: cflecha@us.es

Recepción: 6 de septiembre de 2017. Envío a informantes: I5 de septiembre de 2017 Aceptación definitiva: 30 de octubre de 2017

L

A CONSTRUCCIÓN DE CONOCIMIENTO SOBRE EL PASADO DE LA EDUCACIÓN de las mujeres ha sido objeto de atención desde hace varias décadas; las revisiones bibliográficas realizadas en distintos momentos así lo ponen de manifiesto. Una de ellas, en esta misma revista de Historia de la Educación, realizada por las profesoras Carmen Benso Calvo y Teresa González (2007) dentro de un número dedicado a la historia de la educación de las mujeres (Flecha, 2007a). Es la que nos sirve de punto de partida para la que ahora presentamos sobre el nuevo periodo de 2007 a 2017. Anteriormente, habían hecho este mismo tipo de recopilación las profesoras Pilar Ballarín (1994), Isabel Grana (2004) y Consuelo Flecha (2004).

Las referencias de libros, capítulos, artículos y tesis de doctorado que se incluyen, más de trescientas cincuenta, no agotan las aportaciones al tema en la década revisada, pero sí reflejan suficientemente los aspectos trabajados y las personas que se han ocupado de ellos. La búsqueda ha sido preferentemente de publicaciones sobre educación formal, sobre el acceso de mujeres a los niveles de enseñanza del sistema educativo, o antes a la cultura erudita, aunque también se incluyen algunos trabajos sobre mediaciones de educación no formal. Entre otras características de este elenco observamos una autoría procedente de distintas áreas de conocimiento, sobre todo de educación, historia, filosofía, psicología o ciencias experimentales. 
Comenzamos con una primera presentación de los datos localizados, que han sido agrupados en líneas temáticas para facilitar una visión de conjunto de lo investigado en cada una de ellas (universidad, segunda enseñanza, maestras, escolarización, ciencia, etc.). Y a continuación se incluye el listado completo de referencias citadas.

Las investigaciones sobre cuestiones relacionadas con la presencia de las mujeres en las universidades han experimentado un gran crecimiento en los últimos diez años; en consecuencia, se han publicado los resultados obtenidos en numerosas monografías, capítulos de libros y artículos (Ballarín, 20Iob). En sus páginas encontramos trabajos que, incorporando nuevos análisis, profundizan en la entrada de mujeres a los estudios universitarios, desde el inicio de su ingreso durante el último tercio del siglo xix hasta la Real Orden de 8 de marzo de i9io, normativa que reconoció el derecho que asistía a las mujeres a matricularse en la universidad eligiendo la modalidad de enseñanza más conveniente para cada una, oficial o no oficial, siempre que reunieran los requisitos comunes exigidos (Domínguez, 20ıо; Rodríguez López, 20ıо; Flecha, 20II). Igualmente les fue reconocido el derecho -en otra normativa pocos meses después- al ejercicio profesional de la carrera estudiada (Cuesta, 20I5a). No faltan informaciones que describen los antecedentes de la lenta, pero efectiva, ampliación de oportunidades educativas para las niñas desde principios del siglo XIX y hasta 1936, las cuales fueron favorecieron el paso a los niveles secundarios y universitarios. Una de las contribuciones habla de las dificultades que presentan las fuentes disponibles a la hora de investigar la historia de la presencia de las mujeres en las universidades españolas (Cuesta, Flecha, Matilla, Prado y Rodríguez, 2015), y otra especifica las que custodia el Centro documental de la memoria histórica en Salamanca (Turrrión, 20I5).

Se recuerda a las pioneras de las tres últimas décadas del siglo Xix y a las de generaciones siguientes; en algunos casos, comparando esta misma realidad con lo sucedido en otros países del entorno occidental (Flecha y Palermo, 2008; Cuesta, Prado y Rodríguez, 20I5). Se ha estudiado la evolución cuantitativa de la presencia de mujeres en las universidades españolas (Cuesta, 20I5b) y revisado los rasgos sociales de estas jóvenes de la década de los años veinte del pasado siglo, las $\mathrm{Fa}$ cultades elegidas para matricularse, el ambiente académico que las rodeaba, o su progresiva incorporación a responsabilidades en espacios y asociaciones públicas (Seseña, 2009). También las mediaciones de apoyo a esta educación superior femenina promovidas tanto desde las corrientes más laicas como desde las católicas (Montero, 2009 y 20I0a; Araque, 2015c).

Un extenso trabajo ofrece la historia de las primeras universitarias españolas, de aquellas tres médicas catalanas que accedieron a la Universidad en los años setenta del siglo xix (García Álvarez, 20Io); otros hablan de las pioneras en la Universidad de Valencia (Verdugo, 2013), de las primeras leridanas (Casals, 2016 y 20I7), de médicas de Palencia y de Zaragoza ya en el siglo xx (Miqueo, 2015), de universitarias en Salamanca (Prado, 2015) y en Sevilla (Flecha, 20I6). Se ha rastreado el papel desempeñado por las mujeres en la enseñanza de la bioquímica en la Universidad de Madrid (Basante y Reparaz, 2013). Y hay aportaciones 
sobre alumnas en determinadas carreras (Juan, 2015; Gómez Cuesta, 2015; Causapé, 2017), en universidades concretas (Rodríguez López, 2008; González Pérez, 20I2a; Saavedra, 20I5), o sobre las licenciadas que defendieron el doctorado en la Facultad de Filosofía y Letras (Matilla, 2015). Disponemos igualmente de reseñas biográficas de licenciadas y doctoras (Casals, 2009) dedicadas a la investigación científica, a la educación, al periodismo o a la política en los años veinte y treinta del siglo pasado (Casals, 20Io; Merino Hernández, 20I5; Montero, 20I5).

A pesar de que el contexto y la mentalidad social demostraban muchas reticencias ante este tipo de decisiones -intensificadas en el franquismo- (Pando, 20I5), fue evidente y progresiva su entrada en las aulas universitarias (Capel, 2008; Flecha y Capel, 2009), primero como alumnas y más tarde como profesoras. Así lo ponen de manifiesto los registros bibliográficos, la consulta de fuentes primarias y la lectura de las series históricas de los Anuarios Estadísticos, demostrando las diferencias existentes en la cadencia de ingreso a lo largo de los años (Flecha, 20I5a y b; Guil y Flecha, 20I5) y de acuerdo con la procedencia geográfica. En estos y en otros aspectos se han realizado estudios diacrónicos sobre los logros alcanzados (Miquel, 20Io) después de cien años de prohibiciones (Giménez Salinas, 20Io), por más que persistan variantes significativas en los orígenes, en las tendencias temporales y en los porcentajes de alumnas y de profesoras en cada área de conocimiento, en las diferentes disciplinas académicas y en las categorías profesionales (Poy, 2009; Ballarín, 20I2). Lo cual se revela de manera más clara en las trayectorias dentro de la universidad del franquismo (Saavedra, 20I6).

En la historia de la veterinaria se ha buscado el origen de las mujeres en esa carrera, destacando a la primera mujer que la finalizó en la Escuela de Córdoba en el año 1925, con un retraso de casi cuarenta años respecto de otros países europeos. Sin embargo, el trabajo demuestra que en las últimas décadas del siglo $\mathrm{xx}$ se ha producido una evolución de superioridad numérica de alumnas en estos estudios, aunque esté pendiente compartir en igualdad las oportunidades en los distintos ámbitos profesionales propios de la carrera, en el acceso a niveles de responsabilidad dentro de ellos y en la remuneración económica (Rodríguez Castaño, 20I6). Esta investigación es el fruto de una tesis de doctorado defendida en la Universidad Complutense de Madrid, que recorre la trayectoria femenina en las Escuelas de Veterinaria y en el posterior ejercicio profesional en organismos públicos, en empresas y en otras actividades privadas.

A partir de la segunda década del siglo xx, las licenciadas y doctoras comenzaron a implicarse en el campo de la investigación, especialmente en los centros de la Junta para Ampliación de Estudios, desarrollando este tipo de actividad de manera creciente con el paso de los años (Capel y Magallón, 2007). Están a nuestra disposición varios análisis cuantitativos de esta realidad, de los caminos que las llevaron a lugares donde se creaba ciencia, y de las especialidades en que aportaron su saber antes y después de la Guerra Civil (Morcillo, 2oı́; Rodríguez López, 2013; González Gómez y Payá Rico, 2017).

La monografía sobre las mujeres en la Universidad Internacional de Santander (Folguera, 20IO) ha recuperado una memoria no transmitida hasta ahora, poco 
conocida, dando visibilidad y voz a las alumnas y a las profesoras (Piñón, 20Io) que compartieron el ambiente intelectual de los veranos cántabros antes de la Guerra Civil, y una vez finalizada cuando recuperó su actividad académica (Cuesta, 20Io; Flecha, 20Ioc).

En cuanto a la incorporación a la docencia de profesoras, contamos con algunos trabajos que van mostrando cómo se produjeron los procesos de incorporación (Flecha, 20Iof) y de qué Facultades y materias fueron docentes (Flecha 20I2b; Poveda, 20I5). Igualmente, sobre cómo se insertaron en el ejercicio profesional en diferentes campos, de los cuales he seleccionado algunas de las muchas aportaciones con las que ya se cuenta (Sanchidrián, 2008; Díaz, 20I5).

Se han aportado reflexiones acerca de los códigos de género que han actuado y actúan en las instituciones universitarias españolas, manteniendo una perspectiva cultural androcéntrica y una naturalización de las dependencias y de las desigualdades académicas; no idénticas en cada etapa, pero sí equiparables en cuanto al funcionamiento de estructuras de privilegio masculino (Ballarín, 20I5 y 2017). Tendencia que no termina de rectificarse a pesar de las intervenciones y normativas de igualdad de las que disponemos en España desde hace años (Flecha, 2009b).

En este contexto de atención a los inicios y al desarrollo de la participación de mujeres en las universidades, y como consecuencia de la celebración del primer centenario de la creación de residencias para las estudiantes que se desplazaban a Madrid con la finalidad de estudiar en las diferentes Facultades, vamos conociendo mejor la historia de las que iniciaron esta modalidad de apoyo a principios de siglo (Cuesta, Turrión y Merino, 2015a y b; Cueva y Márquez, 2016), y de algunas otras más tardías.

El fondo documental del archivo de la Residencia de Señoritas de Madrid, en su mayor parte digitalizado, se describe en su volumen y organización en el artículo de Adelina Codina y Rosa San Segundo (2015); en él se subraya la importancia que representa este legado para entender, como merece, el alcance de la actividad desarrollada en ella y su significado en la historia de las mujeres (Canales, 2009). Las nuevas monografías publicadas sobre este centro retoman el origen del grupo universitario femenino de la Residencia de Estudiantes, es decir, la Residencia de Señoritas, cuya apertura se produjo en octubre de i915; documentos que contienen datos de su funcionamiento, actividades docentes y culturales (PérezVillanueva, 20ıг; Vázquez Ramil, 20ı2a), su vida y dinámicas cotidianas (Betrisey, 20I5; Pérez-Villanueva, 20I5b; Ribagorda, 2015). Podemos saber quiénes fueron las jóvenes gallegas que residieron en ella (Vázquez Ramil, 20ı2b) y las jóvenes andaluzas (Lemus, 2016), cómo era la directora María de Maeztu (Pérez-Villanueva, 20Io; Olhaberriague, 20I5) y las relaciones establecidas con personas e instituciones relevantes (Magallón, 2007 y 20I5; Porto Ucha y Vázquez, 20I4). Igualmente exponen la influencia ejercida por las residentes en un amplio entorno de la sociedad del primer tercio de siglo (Vázquez Ramil, 2oısb), los intercambios internacionales en que participaron (Porto Ucha y Vázquez, 2015; Márquez, 2015) y las formas de participar más tarde en la sociedad desde la profesión científica, artística o literaria desempeñada. 
Encontramos además unos primeros estudios sobre la que fue Residencia pionera, la creada en marzo de I9I4 por la Institución Teresiana, para alumnas de la Escuela Superior del Magisterio y de las Facultades universitarias madrileñas. Los datos publicados nos acercan a la finalidad que impulsó su origen, a sus características (Peralta, 2015), y a una descripción, todavía muy general, de las residentes y de los equipos directivos hasta 1936 (Flecha, 20I5c). Sobre otra de las Residencias universitarias abiertas por la misma Institución Teresiana, la de Valladolid, se ha publicado una monografía en la que se hace un recorrido general por la trayectoria seguida desde su apertura en 1931 hasta 1975: el origen, los estatutos, el régimen interno, la procedencia de las alumnas, etc.; primero como Residencia y después como Colegio Mayor femenino «María de Molina», adscrito a la Universidad de Valladolid (Palomares y Rodríguez, 20I3). Otra monografía trata sobre el también Colegio Mayor vallisoletano «Santa María del Castillo» (Palomares, 20Io), y un artículo da noticia de los inicios de la Residencia Zurbarán para alumnas universitarias dirigida por mujeres del Opus Dei en Madrid desde enero de 1947 (Montero, 20Iob).

En cuanto a la segunda enseñanza, se ha comparado el modelo al que se incorporaron las mujeres en España y en otros países del sur de Europa con el adoptado en el mundo anglosajón y del norte europeo. En los primeros, las alumnas compartieron el plan de estudios y, cuando les fue posible matricularse en la modalidad de enseñanza oficial, también las aulas. En los segundos, se crearon centros específicos para mujeres (Canales, 2013), lo que pudo constituir uno de los motivos de que las alumnas de segunda enseñanza crecieran con mayor rapidez. En España las autoridades educativas no habían previsto que las mujeres quisieran elegir este nivel de estudios y, por lo tanto, no sintieron la necesidad de prohibírselos; pero cuando comenzaron las primeras solicitudes de matrícula en el siglo XIX, las candidatas se encontraron con dificultades que, por una razón o por otra, no desaparecieron en mucho tiempo (Benso Calvo, 2007). De ahí que el ritmo de entrada de alumnas, y de profesoras después, se produjera con lentitud, aunque sin perder nunca un ritmo de progreso paulatino (Flecha, 20I0a).

Como en la Dictadura de Primo de Rivera se crearon dos Institutos Femeninos -convertidos en mixtos en la Segunda República-, se ha acometido ya una amplia investigación sobre la enseñanza secundaria femenina en el primer tercio del siglo xx (Araque, 20Ioa). Centrado en el alumnado femenino, se ha realizado un análisis social y académico del Instituto de Ourense, a partir de los datos recogidos en los expedientes personales de las estudiantes matriculadas de 1900 a 1930; informan de las edades de ingreso en el bachillerato, de los cursos y asignaturas estudiadas, del lugar de nacimiento, de la profesión de los padres, de las calificaciones obtenidas y de las instancias cursadas para diferentes solicitudes (Benso Calvo y Cid, 2007). Puede leerse también un artículo acerca de las primeras alumnas de bachillerato en Canarias (González, 2orrb).

Con el franquismo funcionaron de nuevo Institutos Femeninos en casi todas las provincias, que hicieron subir el número de matrículas, pero en medio de resistencias y de debates sobre su conveniencia (Alcalá y Canales, 2009; Canales, 
2012 y 20I7); nivel de enseñanza en el que las estudiantes tenían que completar el plan de estudios general con asignaturas que garantizaran una no total ruptura con la condición tradicional de mujer (Grana, 2007). Se ha empezado a estudiar el Instituto Nacional Femenino de Enseñanza Media Emperatriz María de Austria, abierto en una etapa ya tardía -año 1964- en una zona del extrarradio obrero de Madrid. Una ubicación que facilitó el estudio del bachillerato entre niñas de un grupo social hasta entonces con pocas oportunidades de acceso a este nivel de enseñanza. El artículo incluye información sobre la arquitectura, la distribución de espacios, los órganos directivos, el profesorado y las alumnas (Araque, 2orod).

Las profesoras de Institutos de Segunda Enseñanza han sido otra temática atendida, estudiando las circunstancias de posibilidad, los requisitos de preparación y los ritmos de acceso antes de la Guerra Civil y durante el franquismo, favorecidos cuando el régimen retomó la creación de nuevos Institutos, con el consecuente número de plazas a cubrir (Flecha, 2008 y zorod; Poveda, 20II; Araque Hontangas y Poveda, 20I2; Araque, 20I5a y b; Grana Gil y Martín, 2016). Se han elaborado biografías de algunas de ellas; por ejemplo, de la que fue primera mujer catedrática de Lengua Española y Literatura de Instituto en España, Pilar Díez JiménezCastellanos, con una trayectoria intelectual en el campo de la filología científica (Hernández Andreu y Araque, 2016); de Jenara Vicenta Arnal Yarza, catedrática de Ciencias y directora de uno de los Institutos en los que ejerció (Araque, 2009c); y de María Goyri, profesora vinculada al Instituto-Escuela (Herrero, 20I5). Se ha destacado también la atención prestada por parte de profesoras a diferentes funciones dentro de los Institutos, como la dirección de los mismos (Araque, 2orra y b) o el servicio psicopedagógico (Araque, 2008 y 2009a y b); la misma autora ha escrito sobre la enseñanza de asignaturas del plan de estudios, en concreto la de Religión (Araque, 20IIc). Seguimos conociendo más datos de los procesos de depuración por los que pasaron las profesoras de Instituto con las sanciones que se les aplicaron (Grana, 20I0; Sanchidrián, Grana y Martín, 20II) y las repercusiones del exilio de mujeres artistas en la educación artística (Gaitán, 2016).

La educación física y las mujeres se ha incorporado como uno de los temas más tratados. Se han elaborado dos recopilaciones bibliográficas (Torrebadella, 20II y 2017), analizado cómo fue su presencia en la educación durante el franquismo (Manrique, 2008) y, más concretamente, cómo era impartida la asignatura en un Instituto Femenino de Enseñanza Media (Araque, 20Ioc). Se han investigado y localizado las primeras profesoras de gimnástica que trabajaron en el siglo XIX (Torrebadella, 20I6). Y una tesis de doctorado aporta un recorrido histórico por la educación física de las mujeres centrándose especialmente en la formación de las maestras y profesoras (Gómez García, 2016).

Se han continuado publicando estudios sobre los modelos de educación femenina, tanto a lo largo de la historia como en la actualidad. De los primeros encontramos el que utiliza el género como categoría de análisis de la historiografía griega sobre educación (Dalakoura, 20I6); otro sobre la supuesta docencia femenina en la Hispania romana (Seguí, 20I5); los que describen las propuestas teóricas para la educación de las mujeres en distintos periodos históricos: la de Luis Vives 
en el contexto renacentista de diversidad religiosa y cultural (Viejo, 20I7); la de Erasmus Darwin, que en el siglo XviII defiende la educación pública para las niñas (Cagnolati, 2013); las de las escritoras Ángela Grassi, Pilar Sinués y Faustina Sáez, que construyen el ideal femenino de «ángel del hogar» (Molina, 2016), o el modelo que subyace en el diagnóstico de la situación y en los objetivos señalados por Emilia Pardo Bazán (García Cabeza, 20Io; García Suárez, 2017). Hay varias aportaciones sobre conceptos y sobre prácticas de mujeres (Cabaleiro, 2006-2007), Dewey y su legado feminista (Vaamonde, 2016) o el programa educativo para las mujeres que se desprende del anarquismo (González Pérez, 2013).

La Institución Libre de Enseñanza ha sido tratada en sus diversas aportaciones a la educación de las mujeres. Por ejemplo, acerca de cómo orientaba los planteamientos y las iniciativas dirigidas a la formación femenina (Ballarín, 2008; Cueva, 2015); cuál era el pensamiento de Giner de los Ríos sobre ella (Vázquez Ramil, 20I6); la incidencia que tuvo en la Residencia de Señoritas (Vázquez Ramil, 20I4); su modo de contribuir a una mejor educación de las jóvenes, bien fuese directamente, bien indirectamente o mediante el impulso y colaboración con otras iniciativas, como la Asociación para la Enseñanza de la Mujer (Mandado, Sánchez y Madariaga, 20II), y otras acciones de los krausistas más convencidos (Reig, 20I2).

En este campo de investigación histórico-educativa se ha subrayado el significado que aporta acudir a la memoria y genealogía de mujeres (Flecha, 2007b; Ballarín, 20II), señalando la importancia de formar parte de los planes de estudio universitarios en las Facultades de Educación (Ballarín, 2009; Grana y Rabazas, 2009; Palacio, 2009). Continúan estudiándose las distintas manifestaciones de los procesos de formación de las mujeres a lo largo de los siglos: en la Europa medieval (Lorenzo, 2007; Rodríguez Hernández y Vázquez, 20I4), en el primer Renacimiento (Segura, 2007; García Pérez, 2008 y 2013) y en la etapa postridentina (Patrizi, 20I6), en el magisterio ejercido por las alumbradas en los siglos XVI y XVII (Flecha, 20I5d), en la formación y cultura científica de mujeres en la segunda mitad del siglo XVIII (Serrano y Nieto, 20I2), durante los años del reinado de Isabel II (Espigado, 20IO) y cuando la Ley Moyano de I857 incluyó la escolaridad femenina obligatoria (Sánchez Blanco y Hernández, 20I2). Se han destacado los recursos que incentivaron la alfabetización de las mujeres durante la Segunda República (Aguado, 2013) y su crecimiento en la matrícula de otros niveles educativos (Vázquez Ramil, 20I5a); la capacitación cultural, educativa y profesional impulsada durante la Guerra Civil (Aguado, Agulló y Sanfeliu, 2016) y promovida por mujeres de una y otra zona ideológica (Sánchez Blanco, 2013 y 20I7); las intencionalidades del franquismo acerca de la educación de las mujeres en los distintos niveles de enseñanza (Flecha, 20I5e), en los discursos educativos (Robles, 20Ioc), en la práctica escolar (Frax y Matilla, 2009; Peinado, 20I2; Martínez y Bedmar, 20I6; Sonlleva, 2017) o en la forma de reflejarlo en las imágenes publicadas (Merino Acebes, 20ı0) $\mathrm{y}$ en los testimonios personales (Grana, 2009). En el último tercio del siglo xx, con una evolución marcada por las sucesivas leyes educativas, seguimos aún con desigualdades en su aplicación (González Pérez, 2orob). 
Podemos conocer los modos diversos de educación o de escolarización femenina, en el tiempo y en la geografía, en algún trabajo de síntesis histórica (Amo, 2009), durante la alta Edad Media (Sánchez Prieto, 20Io), en las Escuelas de Amigas desde el siglo xvi al xx en Andalucía y en las dos Castillas (Cano, 20Io), en los colegios de religiosas Ursulinas del XVI al XIx (Espino, 20I7), en la ciudad de Ferrol en el trascurso de los siglos XviII al xx (vv. AA., 20Io), en las mujeres gitanas desde el siglo xv al xxI (Salinas, 20I5a y b), en la política ilustrada de creación de escuelas de primeras letras para niñas (Vales y Reder, 2015) y la influencia que estas escuelas tuvieron en México para el impulso a la alfabetización femenina (Arredondo y González, 2013).

Durante el periodo ilustrado, cuando empieza a pensarse en una instrucción pública como deber de Estado y necesaria para el progreso social, son numerosos los planteamientos e iniciativas que surgen a favor de la educación de las mujeres (Capel, 2007; Aragón, 2008; Perrupato, 20I4-2015). Los encontramos en Galicia (Sixto, 20I6), en el Seminario de niñas de Bergara (Ayerbe, 2008), en las escuelas de Girona y de Vic (Puig, 20Io), en los colegios para la educación de niñas huérfanas de Madrid (Comella, 20I2), en los programas de formación profesional de las escuelas matritenses (Méndez, 20I7), en la apertura y funcionamiento de la Escuela de La Paz en Madrid (González Barrero, 20I7), en la enseñanza reglada para matronas desde finales del siglo xviıI (Ruiz, 20I3) y en su implantación en Sevilla (Bernal y Calero, 20r6), en la educación de reinas y de princesas (López Cordón, 20I4) y en la vindicación del derecho de todas las mujeres a ser instruidas defendida por Mary Wollstonecraft (2010 y Robles, 2013).

También son muy abundantes los trabajos centrados en diferentes aspectos de la educación femenina durante el siglo xix y parte del xx. Los ideales que la guiaban (Hernández Gómez, 20I4), una inicial enseñanza profesional para mujeres (Rico, 20IO y 20I2), pero, de manera especial, los procesos de escolarización investigados en numerosas localidades: Estepa, en la provincia de Sevilla (Flecha, 2007e); Mataró, provincia de Barcelona (Gurrera, 20Io); Los Santos de Maimona, provincia de Badajoz (Soto, 20Io); en toda la provincia de Jaén en el siglo XIX (Cruz y Sancho, 20I5), en el siglo xx (Sancho y Cruz, 2015) y en algunos de sus pueblos como Martos y Jamilena (Gutiérrez Pérez, 20Iob) o Jódar (Rivera, 20I2); en Galicia (García Fernández, 20I2), La Coruña (Porto y Vázquez, 2013); Cádiz (Vázquez Domínguez, 20I6); Berja, en la provincia de Almería (Callejón, 20I2), y algunos más. Se desvelan las reticencias hacia un avance en la creación de escuelas de niñas que se desprenden de las políticas educativas (Gabriel, 2or3; Flecha, 2013a; García Perales y Martín, 2013), y se consolida la legitimación de una sociedad de esferas separadas (Ballarín, 2007a; Sánchez Vidal, 20I6), no solo en España sino también en otros países europeos (González Pérez, 20ı2b).

De los organismos públicos que ofrecían enseñanza a las niñas, encontramos también información sobre Canarias (González Pérez, 2007), A Coruña (Branco, 2009; Gómez Gómez, 20I5; Gómez Gómez y Escudero, 2016), Galiza (Mariño, 2013), Asturias (García Galán, 2016) o Cádiz (Vázquez Domínguez, 20ı6). Y sobre instituciones privadas, la contribución de la Escuela de Paula Montal (Pérez 
Marín, 20I4), la Institución Teresiana (Rosique y Peralta, 20I2; Valle, 20I4; Peralta, 20I4; Samaniego, 20I4), el Instituto de Cultura y Biblioteca Popular para la Mujer de Barcelona (Duch, 20I5) y la Escuela del Hogar y Profesional de la Mujer (Pérez Villanueva, 2orsa; Cotelo, 20I6).

Otras iniciativas privadas fueron el Centro Iberoamericano de Cultura Popular Femenina (Ezama, 2017), los colegios de las Vedrunas (Berdote, Dávila y Naya, 20I5; Berdote, 20I6), los de las hermanas Carmelitas de la Caridad (Berdote y Miguelena, 20I6), las escuelas vicencianas de Luisa de Marillac (Torres Alé, 2017), otras instituciones religiosas de enseñanza en Alicante (Flecha, 2009c) o en Vigo (Piñero, 2013), las educadoras estadounidenses en España (Huguet, 20I5) y el apoyo de las propuestas de Pedro Poveda a que las mujeres se dedicaran al estudio y a la ciencia (Flecha, 2009a).

También ha sido investigada la enseñanza de algunas disciplinas como la música (García Gil y Pérez, 20I6), los referentes morales específicos para las niñas (Robles, 2007a), la preparación en economía doméstica (Carreño y Rabazas, 2008 y 20I0) y el hecho de que las mismas capacidades de las mujeres no reconocidas para un tipo de funciones públicas sí se resaltaran para las domésticas (Robles, 2009), o la importancia de actividades como las Conferencias dominicales de la Asociación para la Enseñanza de la Mujer (García Romero, 2013). Han continuado despertando atención los procedimientos utilizados en la educación para la maternidad (Palacio, 2007 y 20II), los discursos sobre el desarrollo de las destrezas propuestas e impuestas como imprescindibles en una mujer (González Pérez, 2008a) y la existencia de la Escuela Nacional de Maternología (Colmenar, 2009), así como el apoyo que daban las revistas a esta formación (Guichot, 2013). Los Museos Pedagógicos son un explícito testimonio de cómo se ha enseñado a ser mujer en la escuela (Rebollo, 20I5), lo mismo que las diferencias de género reflejadas en los manuales pedagógicos destinados a la formación de maestras (Rabazas, 2013) y muchos de los recuerdos de la educación recibida que aparecen en las autobiografías de mujeres (González Sanz, 20II-20I2).

Un grupo de aportaciones se refieren a la responsabilidad que se le asignó a la Sección Femenina tanto en la enseñanza formal como en la educación no formal de las mujeres (Aguilar, 2015). Podemos conocer la formación de los mandos e instructoras (Manrique Arribas, López, Torrego y Mongas, 2008) y su contribución en el mundo rural al desarrollismo español (Ramos y Rabazas, 2007; Ramos, 20I4, 20I6a y 20I6b), en concreto sus actuaciones en la provincia de Badajoz (Real, 20I3). También la capacitación y empoderamiento de mujeres en ese mundo a través de diferentes recursos utilizados por la Sección Femenina (Pérez Moreno, 2008; Ramos y Colmenar, 20I4; Ramos, 20I6c), la socialización y cultura difundida (Prieto, 20Io), y el papel desempeñado por las revistas (Rebollo y Núñez, 2007; Martínez y Alfonso, 2013; Cenarro, 20I7; Ofer, 2017), la publicidad (Núñez y Espinosa, 2013), el cine (Gutiérrez, 20I6), las historietas sentimentales (Jiménez, 20II) o la música (García Gil y Pérez, 20I7).

Después de la Guerra Civil, las finalidades prescritas por el franquismo aparecen sintetizadas en "Dios, patria y hogar” (González Pérez, 20I4a). Habrá que 
esperar casi hasta los años de la transición política para que emerjan las urgentes exigencias de igualdad en la educación, con discursos y con estrategias orientadas a acelerar el itinerario que conducía hacia una escuela coeducativa (Robles, 20Iob), destacando el papel fundamental que jugaron muchas educadoras en este quehacer (Robles, 20I5).

Los trabajos sobre maestras abarcan desde su presencia en las escuelas de Navarra del siglo xviII (Gárriz, 20II) hasta el último tercio del xx, investigando el origen de la actuación de mujeres en aulas creadas por organismos públicos, un ámbito laboral donde las mujeres lograron pronto espacios de reconocimiento fuera de los espacios familiares. Destacan su incremento cuando la escolarización de las niñas se hizo obligatoria, se analizan los planes de formación en diferentes épocas y se hace memoria de trayectorias docentes valiosas. Contribuciones que las consideran como uno de los grupos que ha despertado especial curiosidad y que, al igual que todas las anteriores, han de situarse en el ámbito de la historia de las mujeres. En unos casos para destacar la labor educadora realizada dentro y fuera de la escuela (Arce, 20I3; Calderón España, 2008; Ledesma, Peinado, Sancho, García y Rueda, 20I4); subrayar el tipo de enseñanzas que algunos ayuntamientos les reclamaban como prioritarios para las niñas de su localidad (Gallego, 2013; Agulló, 20I6); destacar sus aportaciones a la renovación pedagógica (González Pérez, 20IIa), y, de manera específica, las de maestras andaluzas en la Edad de Plata (Ballarín, 20r6), de maestras extremeñas (Collado, 20II) o de maestras catalanas, en este caso a través de revistas como Feminal (Sureda, Motilla y Comas, 20I4). Se ha relatado, aprovechando fuentes orales de maestras, cómo apoyaron la alfabetización en Canarias (González Pérez, 2008b), y la incidencia del pensamiento pedagógico de Giner de los Ríos en algunas de ellas, como Berta Wilhelmi (Ballarín, 20r3a). En otros trabajos, recuperando la memoria y valorando la labor desempeñada no solo en las aulas, sino, además, en virtud de los compromisos políticos contraídos (Martorell, 20I4-20I5), de la actividad como escritoras (Ballarín, 20I0a) y de los procesos de depuración que les afectaron (Agulló, 2009; Ramos 2013).

Las maestras de la República y su ejercicio profesional a favor de una educación ciudadana han sido objeto de numerosas publicaciones, varias de ellas disponibles en un mismo libro que recoge las ponencias expuestas en las Jornadas «Las maestras de la República. Una historia para el recuerdo», organizadas por la Fundación Pablo Iglesias y FETE-Ugt (Sánchez de Madariaga, 2OI2a). En ellas se expone una visión general (Sánchez de Madariaga, 20I2b; Agulló, 20I2; Flecha, 20I2a) y se analiza la categoría de «maestra republicana» (Pozo, 20I2) valiéndose de relatos literarios (Calderón Puerta, 20I2), recordando a las que salieron al exilio en la Guerra Civil (Guardia, 20I2) y poniendo de relieve sus ideales y metodologías innovadoras. Igualmente, hay estudios sobre las educadoras en la Guerra Civil (García Colmenares, 20I2; Lafoz, 20I2) y en el franquismo (González Pérez, 20ı4b; Domenech, 20I6), sobre la represión sufrida por las maestras republicanas (Negrín, 2012; Ramos, 2012; Alvarado, 2015) y sobre otro tipo de sanciones (Poy, 20II). 
Se han analizado los programas de formación inicial de maestras en el siglo xIX (González Pérez, 20ı0a) y una legislación que la regulaba imprimiendo diferencias entre maestras y maestros hasta en el modo de seleccionar los contenidos de la geometría (Meavilla, 20I6), la preparación específica de las maestras parvulistas (Diego y González, 20II), los factores que en el primer tercio del siglo xx incidieron en el abandono de los estudios de magisterio (Ramírez, 20I2), alguna de las instituciones privadas que en este mismo periodo se ocuparon de la formación de maestras (Quesada, 20I6) y los drásticos cambios en la formación del magisterio durante el franquismo (Araque, 2009d). También se registran referencias al acceso a la profesión en el siglo xix (Cortada, 20II) y a los exámenes de oposiciones para desempeñar el cargo de directora de Escuela Normal (Cid, 20I5), así como un acercamiento a la historia de la Escuela Normal de Teruel como un centro que contribuía a la igualdad (Abós, 2013).

No se ha omitido hablar sobre el pensamiento educativo de algunas maestras (Fernández, 20I2), sobre su identidad personal propia, la que se esperaba en ellas y la transmitida en los manuales escolares (Rabazas y Ramos, 20II; Risueño, 20II; Ibáñez, 2016), los perfiles profesionales y sociales que estaban vinculados a la tarea educativa (San Román, 2007; Robles, 2007b y 2008; Flecha, 20Iob). En el caso de Logroño, se han analizado su origen social, la formación recibida y cómo se fueron insertando en el sistema educativo desde mediados del siglo xIx hasta la actualidad (Giró, 2009).

Se han publicado biografías de maestras que alcanzaron un relieve especial por su actuación profesional en la escuela, en el entorno en que se desenvolvían o como autoras de manuales de contenido pedagógico (Comas, 2009; Jimeno, 2009; Pozo, 20I3; Villa, 2013; Valbuena, 2015); de algunas inspectoras de enseñanza primaria (Rabazas y Ramos 2007; Gómez San Miguel, 2016), y de las que lideraron proyectos de educación de mujeres (Sánchez Morillas, 20II). Han suscitado interés las características y compromisos educativos vividos por las maestras rurales, las más numerosas durante muchas décadas en España, en escuelas unitarias muy habitualmente (Sánchez Morillas, zoIO y 20I2; Gutiérrez Pérez, 20IO). También se ha publicado en estos últimos años sobre maestras en otros países; por ejemplo, sobre una educadora chilena (Guil y Vera, 20Io), sobre una profesora portuguesa (Hernández Díaz, 20I2), sobre la formación de las maestras de parvulario en Chile (Socías, 20I4) o sobre los cambios exigidos en Italia a maestros y maestras durante el fascismo (Fort, 2015).

Hay aportaciones que han querido comprobar la aplicación del modelo coeducativo que las autoridades ministeriales de la Segunda República quisieron extender a todos los niveles de enseñanza, y cómo se promovió en un caso concreto, la Escuela Normal de Sevilla (Rueda, 2009). También se ha considerado la influencia de las propuestas coeducativas del movimiento feminista en las décadas de la transición (Robles, 20IOa), así como el camino recorrido hasta llegar a conseguir que fuera realidad la integración de alumnas y alumnos en las mismas aulas durante las dos últimas décadas del siglo xx, al menos en la modalidad de enseñanza mixta (Calvo, Susinos y García, 20II). Se ha producido de forma paralela a los procesos de 
feminización que han traído consigo nuevas oportunidades (Gabriel, 20I4), pero, a la vez, manteniendo barreras en el control de tránsito a diferentes funciones, entre otras al desempeño de cargos directivos (Rabazas y Villamor, 2008 y 2009). Y cuando se ha ejercido la función directiva, los sistemas de acceso (Rabazas et al., 20I2) y los estilos aplicados (Rabazas y Vallamor, 20ı).

Podemos fijarnos también en un conjunto de colaboraciones que ofrecen hechos y semblanzas de mujeres que cultivaron saberes científicos, artísticos o literarios en diferentes momentos históricos, ellas mismas o poniendo los medios para incentivarlos a su alrededor; por ejemplo, la escuela palatina de la reina Isabel la Católica en la que ella, sus hijas y las jóvenes de la corte aprendían, en el contexto del Renacimiento, con intelectuales ilustres (Val, 20II; Ferrer, 20I7). Van siendo visibilizadas las mujeres científicas en la historia (Matilla y Mó, 20I4) y las dedicadas a determinados saberes. Así, las encontramos en la filosofía (Gleichauf, 20Io), la matemática y astronomía (Contu, 2009), las ciencias experimentales (Magallón, 20ıо; Romero, 2017), la psicología (García Colmenares, 20II; Guil y Vera, 20I5; Guil, 20I6), la psiquiatría (Araque, 20Iob), las ciencias naturales (Delgado, 2007 y 2009), la música (García Gil y Pérez, 20I4a y b, 20I7a), la medicina (Groves y López, 2015), la investigación científica (Pérez y Canales, 20I3) o la docencia y creación artística (Torres, 2007 y 20I0). Se habla de varias mujeres en publicaciones de autoría colectiva (Alcalá, Corrales y López, 2009a; Muñoz y Ballarín, 20Io) o en comunicaciones presentadas en Congresos (Casado et al., 2015; Val y Martínez, 20I5; García Gil, Flecha et al., 20I6). De igual forma, hay trabajos que se acercan a esta temática en términos más generales (Ballarín, 2007b; Flecha, 2013b).

Los vínculos entre mujeres y ciencia han despertado valoraciones de conjunto destinadas a visibilizar el avance que se ha producido en un ámbito de conocimiento, los Estudios de las Mujeres, en el que muchas académicas e investigadoras ponen tiempo y ánimo desde una epistemología que no prescinda de la mirada de las mujeres (Flecha, 2007d y 20Ioe; Cagnolati, 2009; Gálvez, 20I6); e, igualmente, deteniéndose en una docencia que ha de incluir la perspectiva de género, cualquiera que sea la disciplina de que se trate (Flecha, 2007c; Ballarín, 2017), aunque haya de convivirse con resistencias y prejuicios (Ballarín, 2013b).

En el caso de la Historia de la Educación, comprobamos en estas páginas que tenemos disponible un amplísimo bagaje de conocimiento para ser incorporado a cada una de las disciplinas históricas que forman parte de los planes de estudio de las Facultades de Educación. 
UNA DÉCADA DE PUBLICACIONES SOBRE HISTORIA DE LA EDUCACIÓN

DE LAS MUJERES (2007-2OI7)

CONSUELO FLECHA GARCÍA

\section{Bibliografía}

Aвós Olivares, Pilar: «La Escuela Normal de maestras de Teruel, un centro para la igualdad (I857-190I)», Historia de la Educación: Revista Interuniversitaria, 32 (2013), pp. 2II-242.

Aguado, Ana M.: «La República de las ciudadanas: libertad, ciudadanía femenina y educación durante la Segunda República», en Espigado Tocino, M. Gloria; Gómez Fernández, Juan; Pascua Sánchez, María José de la; Sánchez Villanueva, Juan Luis y Vázquez Domínguez, Carmen (eds.): La Constitución de Cádiz: genealogía y desarrollo del sistema educativo liberal, Cádiz, Universidad de Cádiz, 2013, pp. 577-588.

Aguado, Ana M.; Agulló Díaz, Carmen y Sanfeliu, Luz: «Dones i Guerra Civil: política, cultura i educació a la València capital de la República», en València capital de la República: 1936-1937. I, El món mira a València, capital de l'antifeixisme, València, Ajuntament de València, Regidoria de Patrimoni Cultural i Recursos Culturals, 2016, pp. I35-16o.

Aguilar Carrión, Isabel: «Educación e ideología artística de género en las revistas de sección femenina: una comparación entre "Medina" e "Y para la mujer" (1939-1945)", en Folguera, Pilar; Pereira Castañares, Juan Carlos; García García, Carmen; IzQuierdo Martín, Jesús; Pallol Trigueros, Rubén; Sánchez García, Raquel; Sanz Díaz, Carlos y Tовоso SÁnchez, Pilar (coords.): Pensar con la historia desde el siglo XXI: actas del XII Congreso de la Asociación de Historia Contemporánea, Madrid, Universidad Autónoma de Madrid, 20I5, pp. I09I-IIO4.

Agulló Díaz, Carmen: «La depuració de les mestres valencianes: de l'esperança a la derrota», en Pagès I Blanch, Pelai (coord.): La repressió franquista al País Valencià: Primera Trobada d'Investigadors de la Comissió de la Veritat, València, Edicions Tres i Quatre, 2009, pp. 195-227.

Agulló Díaz, Carmen: «El papel de las maestras en la escuela republicana», en SÁnCHez DE Madariaga, Elena (ed.): Las maestras de la República, Madrid, Los Libros de la Catarata, 2012, pp. 56-90.

Agulló Díaz, Carmen: «Les germanes Pepita i Elisa Úriz: més enllà de la pedagogía», Perspectiva Escolar, 388 (2016), pp. 68-69.

Alcalá Cortijo, Paloma y Canales Serrano, Antonio Fco.: «Paisaje después de la batalla», en Alcalá Cortijo, Paloma; Corrales Rodrigáñez, Carmen y López Giráldez, Julia (coords.): Ni tontas, ni locas. Las intelectuales en el Madrid del primer tercio del siglo XX, Madrid, FECYT, 2009, pp. 238-24I.

Alcalá Cortijo, Paloma; Corrales Rodrigáñez, Capi y López Giráldez, Julia: Ni tontas, ni locas: las intelectuales en el Madrid del primer tercio del siglo XX, [Madrid], Fundación Española para la Ciencia y la Tecnología, 2009a, 254 pp.

Alvarado Iglesias, Rodrigo: "A primeira etapa do proceso de depuración de mestres e mestras de primeiro ensino na provincia de Lugo: agosto-novembro de 1936», Sarmiento: Anuario Galego de Historia da Educación, I8-I9 (2015), pp. III-I28.

Amo del Amo, M. ${ }^{a}$ Cruz del: «La educación de las mujeres en España: de la amiga a la universidad», Participación Educativa, II (2009), pp. 8-22.

Aragón Fernández, María Aurora: «Las ideas de la Ilustración francesa sobre la mujer y su educación», Cuadernos de Investigación, 2 (2008), pp. I03-142.

Araque Hontangas, Natividad: «Maximina Pilar Díaz-Peñalver y Colino, creadora y directora del primer Gabinete de Orientación de un Instituto de Enseñanza Media», Faisca: Revista de Altas Capacidades I3, I5 (2008), pp. 50-64.

Araque Hontangas, Natividad: «El servicio psicopedagógico en los institutos femeninos de enseñanza media a mediados del siglo xx», Revista de Historia de la Psicología, 30, 2-3 (2009a), pp. 29-38.

Araque Hontangas, Natividad: «La creación del Gabinete Psicotécnico del Instituto Femenino Isabel la Católica de Madrid (I956-57)», en Berruezo Albéniz, María Reyes y Conejero 
López, Susana (coords.): El largo camino hacia una educación inclusiva: la educación especial $y$ social del siglo XIX a nuestros dias: XV Coloquio de Historia de la Educación, PamplonaIruñea, $2009 \mathrm{~b}, \mathrm{pp} .573-582$.

Araque Hontangas, Natividad: «Jenara Vicenta Arnal Yarza: una científica y catedrática pionera en España», Faisca: Revista de Altas Capacidades, I4, I6 (2009c), pp. 27-49.

Araque Hontangas, Natividad: «La formación de las maestras durante la primera etapa del Franquismo», Tendencias Pedagógicas, I4 (2009d), pp. II7-I28.

Araque Hontangas, Natividad: La educación secundaria femenina I900-1930, Madrid, Editorial Complutense, 20I0a, $408 \mathrm{pp}$.

Araque Hontangas, Natividad: «Karen Horney: una doctora que revolucionó el mundo de la psiquiatría durante la primera mitad del siglo xx», Faisca: Revista de Altas Capacidades, I5, I7 (20I0b), pp. III-I35.

Araque Hontangas, Natividad: «La educación física como moldeador del cuerpo y de la mente en el Instituto Femenino de Enseñanza Media Isabel la Católica, de Madrid (19391984)», Cuadernos Unimetanos, 2I (2010c), pp. 9-20.

Araque Hontangas, Natividad: «El Instituto Nacional Femenino de Enseñanza Media Emperatriz María de Austria de Madrid (1964-1970)», Revista Complutense de Educación, 2I, I (2olod), pp. 73-88.

Araque Hontangas, Natividad: «Las primeras directoras de Institutos de Enseñanza Media en Madrid», en Celada Perandones, Pablo (ed.): Arte y oficio de enseñar: dos siglos de perspectiva histórica. xvi Coloquio Nacional de Historia de la Educación, Soria, El Burgo de Osma, 2, 20Ira, pp. 56I-568.

Araque Hontangas, Natividad: «La enseñanza de la religión en el Instituto Nacional Femenino de Enseñanza Media Isabel La Católica de Madrid durante el franquismo», Historia de la Educación: Revista Interuniversitaria, 30 (20IIb), pp. 22I-240.

Araque Hontangas, Natividad: «Las primeras pensionadas y catedráticas de latín y lengua y literatura», en PAdrós, Núria; Collelldemont, Eulàlia y Soler, Joan (eds.): Arte, literatura y educación, Vic, Universitat de Vic-Universitat Central de Catalunya, vol. 2, 20I5a, pp. II-I7.

Araque Hontangas, Natividad: «Las mujeres pioneras en la docencia y dirección en centros de educación secundaria en España y su vinculación con la Junta de Ampliación de Estudios y el Consejo Superior de Investigaciones Científicas en el s. XX», en Casado Mejía, Rosa; Flecha García, Consuelo; Guil Bozal, Ana; Padilla-Carmona, María Teresa; VÁzquez Bermúdez, Isabel y Martínez Torres, María del Rocío (coords.): Aportaciones a la investigación sobre mujeres y género, Sevilla, siEmus, 20I5b, pp. 440-444.

Araque Hontangas, Natividad: «La influencia del liberalismo en el acceso de las mujeres a la educación superior y su protección internacional a través de la Junta de Ampliación de Estudios», en Folguera, Pilar; Pereira Castañares, Juan Carlos; García García, Carmen; Izquierdo Martín, Jesús; Pallol Trigueros, Rubén; Sánchez García, Raquel; Sanz Díaz, Carlos y Toвoso Sánchez, Pilar (coords.): Pensar con la historia desde el siglo XXI: actas del XII Congreso de la Asociación de Historia Contemporánea, Madrid, Universidad Autónoma de Madrid, 20I5c, pp. II95-I208.

Araque Hontangas, Natividad y Poveda Sanz, María: «La presencia de las mujeres en la segunda enseñanza en Madrid (I9IO-1936)», en López-Ocón CABrera, Leoncio; ArAgón, Santiago; Pedrazuela Fuentes, Mario y Juaristi, Jon (coords.): Aulas con memoria: ciencia, educación y patrimonio en los Institutos históricos de Madrid (I837-1936), 20I2, pp. 209-224.

Araque Hontangas, Natividad y Villa Fernández, Nuria: «La labor de las primeras directoras de los Institutos de Enseñanza Media de Madrid: Beatriz Galindo y Emperatriz María de Austria», Participación Educativa, Extra I (2011), pp. 225-239. 
Arce Díez, Pedro: "Aurora Gutiérrez Galante: Semblante de una Maestra a su paso por La Albericia (Cantabria), en el Centenario de su Nacimiento (1913-2013)», Cabás, го (2013), pp. I09-I42.

Arredondo, Adelina y González Pérez, Teresa: «Más allá del tiempo y el espacio: un modelo pedagógico para las niñas desde la España ilustrada al México republicano», Clepsydra: Revista de Estudios de Género y Teoría Feminista, I2 (2013), pp. I25-138.

Ayerbe Iríbar, María Rosa: «Manuel de Larramendi y la enseñanza femenina en el s. XviII. Constituciones del Seminario de niñas "Nuestra Señora de la Soledad”, de Bergara (I74I)", Boletín de la Real Sociedad Bascongada de Amigos del País, 64, 2 (2008), pp. 795-815.

Ballarín Domingo, Pilar: «La educación contemporánea de las mujeres», en GuereÑa, JeanLouis; Tiana Ferrer, Alejandro y Ruiz Berrio, Julio (coords.): Historia de la educación en la España contemporánea: diez años de investigación, Madrid, Ministerio de Educación Cultura y Deporte, Centro de Investigación y Documentación Educativa 1994, pp. 173-190.

Ballarín Domingo, Pilar: «La escuela de niñas en el siglo xix: la legitimación de la sociedad de esferas separadas», Historia de la Educación: Revista Interuniversitaria, 26 (2007a), pp. I43-I68.

Ballarín Domingo, Pilar: «Saberes de las mujeres y saber oficial», en Medina Guerra, Antonia María (coord.): Avanzando hacia la igualdad, Málaga, Diputación-Asociación de Estudios Históricos sobre la Mujer, 2007b, pp. 2I-38.

Ballarín Domingo, Pilar: «Las mujeres de la Institución Libre de Enseñanza», en CarantoÑa Álvarez, Francisco y Aguado Cabezas, Elena (coords.): Ideas reformistas y reformadores en la España del siglo XIX: los Sierra Pambley y su tiempo, Madrid, Biblioteca Nueva, 2008, pp. 290-314.

Ballarín Domingo, Pilar: «Importancia de la inclusión de la historia de la educación de las mujeres en los planes de estudio universitarios», en vv. AA.: Historia de la Educación de las Mujeres, Murcia, Sociedad Española de Historia de la Educación, 2009, pp. 33-44.

Ballarín Domingo, Pilar: «Adela Riquelme, profesora y escritora decimonónica», en MuÑoz Muñoz, Ana M. y Ballarín Domingo, Pilar (coords.): Mujeres y libros: homenaje a la profesora Dña. Isabel de Torres Ramírez, Granada, Editorial Universidad de Granada, 2010a, pp. 19-36.

Ballarín Domingo, Pilar: «Entre ocupar y habitar. Una revisión historiográfica sobre mujeres y Universidad en España», Arenal: Revista de Historia de Mujeres, I7, 2 (20Iob), pp. 223-254.

Ballarín Domingo, Pilar: «Memoria de la educación de las mujeres», en Lomas, Carlos (coord.): Lecciones contra el olvido, memoria de la educación y educación de la memoria, Madrid, Ministerio de Educación Cultura y Deporte, Secretaría General Técnica, 2orra, pp. 77-IIO.

Ballarín Domingo, Pilar: «Traslaciones de las maestras españolas de entre siglos XIX-XX», en Celada Perandones, Pablo (ed.): Arte y oficio de enseñar: dos siglos de perspectiva histórica, XVI Coloquio Nacional de Historia de la Educación, Soria, El Burgo de Osma, vol. 2, 20IIb, pp. 35-44.

Ballarín Domingo, Pilar: «La feminización del ámbito de historia de la educación en las universidades españolas», en Díaz Sánchez, Pilar; Franco, Gloria A. y Fuente Pérez, María Jesús (ed.): Impulsando la historia desde la historia de las mujeres: La estela de Cristina Segura, Huelva, Universidad de Huelva, 20I2, pp. II7-I30.

Ballarín Domingo, Pilar: «El influjo de Francisco Giner de los Ríos en Granada: Berta Wilhelmi», en Jiménez Estrella, Antonio; Lozano Navarro, Julián José; Sánchez Montes, Francisco y Birriel Salcedo, Margarita María (eds. lit.): Construyendo historia: estudios en torno a Juan Luis Castellano, Granada, Universidad de Granada, 2013a, pp. 47-53.

Ballarín Domingo, Pilar: "Docencia universitaria y conocimiento en torno al género. Resistencias, creencias y prejuicios», Cuestiones de Género: de la Igualdad y la Diferencia, 8 (2013b), pp. 89-106. 
Ballarín Domingo, Pilar: «Los códigos de género en la universidad», Revista Iberoamericana de Educación, 68 (2015), pp. 19-38.

Ballarín Domingo, Pilar: «La contribución de las maestras andaluzas a la renovación pedagógica en la Edad de Plata», en Lemus López, Encarnación: Renovación en las aulas. La Institución Libre de Enseñanza en Andalucía, Sevilla, Centro de Estudios Andaluces, 2016, pp. 45-63.

Ballarín Domingo, Pilar: «Las fronteras de la docencia universitaria feminista en tiempos revueltos», en Gallego Franco, Henar; Moreno Seco, Mónica y Pedregal Rodríguez, María Amparo (coords.): Cómo enseñamos la historia (de las mujeres): homenaje a Amparo Pedregal, Barcelona, Icaria, 20I7, pp. 5I-74.

Basante Pol, Rosa y Reparaz de la Serna, Guillermo: «El papel de la mujer en las enseñanzas de bioquímica en la Facultad de Farmacia de la Universidad de Madrid durante la autarquía en España», Anales del Instituto de Estudios Madrileños, 53 (2013), pp. 349-378.

Benso Calvo, M. Carmen: «Cambios y resistencias en el bachillerato a principios del siglo xx: currículo, coeducación y formación del profesorado en los Congresos Internacionales de Segunda Enseñanza», Revista de Ciencias de la Educación: Órgano del Instituto Calasanz de Ciencias de la Educación, 2II (2007), pp. 289-317.

Benso Calvo, M. Carmen y Cid Galante, Rosa María: «Los expedientes de las estudiantes de bachillerato: una fuente básica para el estudio del alumnado femenino de los Institutos. Ourense como ejemplo (1900-1930)», Historia de la Educación: Revista Interuniversitaria, 26 (2007), pp. 437-470.

Benso Calvo, Carmen y González Pérez, Teresa: «Bibliografía sobre historia de la educación de las mujeres en España», Historia de la Educación. Revista Interuniversitaria, 26 (2007), pp. 483-517.

Berdote Alonso, Esther: «Mujer y educación. El caso de las Vedrunas en el País Vasco, siglos XIX y XX», Historia y Memoria de la Educación, 4 (2016), pp. I07-I39.

Berdote Alonso, Esther; Dávila Balsera, Paulí y Naya Garmendia, Luis María: «Pedagogical Renewal and Second Vatican Council: the Cases of The Salle Brothers and the Vedrunas in the Basque Country", Social and Education History, 4, 3 (2015), pp. 238-259.

Berdote Alonso, Esther y Miguelena Torrado, Joana: «Formación religiosa y vocacional de la mujer impartida por las Hermanas Carmelitas de la Caridad en el País Vasco tardofranquista», en Dávila Balsera, Paulí y Naya Garmendia, Luis María (coords.): Espacios y patrimonio histórico-educativo, Donostia, Erein, 2016, pp. 233-244.

Bernal Borrego, Encarnación y Calero Delgado, María Luisa: «La implantación de la enseñanza de matronas en la Universidad de Sevilla (I86I)», Arenal: Revista de Historia de las Mujeres, 23, 2 (2016), pp. 403-430.

Betrisey Nadali, Débora: «La Residencia de Señoritas: formas de contar y re-contar», en Cuesta, Josefina; Turrión, María José y Merino, Rosa María (eds.): La Residencia de Señoritas y otras redes culturales femeninas, Salamanca, Ediciones Universidad de Salamanca, Madrid, Fundación Ortega y Gasset-Gregorio Marañón, 2015, pp. 267-286.

Branco BuxÁn, Xosé Ramón: «A muller e o sistema educativo: actitudes sociais, poder político e ideoloxía dominante: estudio dun caso: Concello de A Coruña 1970-1985», Sarmiento: Anuario Galego de Historia da Educación, I3 (2009), pp. IoI-I30.

Cabaleiro Manzanedo, Julia: «Pensament i pràctiques de les dones sobre l'educació femenina: un recorregut a través del temps», Educació i Història: Revista d'Història de l'Educació, 9-IO (2006-2007), pp. 50-69.

Cagnolati, Antonella: "Historia de la educación y "Women's History": perspectivas de la investigación contemporánea en ámbito educativo en Italia (2000-2008)», en BERRUEzo Albéniz, María Reyes y Conejero López, Susana (coords.): El largo camino hacia una educación inclusiva: la educación especial y social del siglo XIX a nuestros dias: XV Coloquio de Historia de la Educación, Pamplona-Iruñea, vol. I, 2009, pp. 687-698. 
Cagnolati, Antonella: «Ilustración y educación de las mujeres: las propuestas de Erasmus Darwin», en Espigado Tocino, M. Gloria; Gómez Fernández, Juan; Pascua Sánchez, María José de la; Sánchez Villanueva, Juan Luis y VázQuez Domínguez, Carmen (eds.): La Constitución de Cádiz: genealogía y desarrollo del sistema educativo liberal, Cádiz, Universidad de Cádiz, 2013, pp. 23-34.

Calderón España, Consuelo: «María de la Encarnación de Rigada y Ramón», en CorTs GINer, Isabel y Calderón España, Consuelo (coords.): Estudios de historia de la educación andaluza (siglos XVIII, XIX Y XX), Sevilla, Universidad de Sevilla, 2008, pp. I69-178.

Calderón Puerta, Aránzazu: «Mujer y emancipación en tiempos de la República: "Historia de una maestra”, de Josefina Aldecoa», Sociocriticism, 27, I-2 (2012), pp. I47-I74.

Callejón Callejón, Ana María: «Mujer y primera enseñanza en el partido judicial de Berja (finales del siglo XIX-primera mitad del siglo Xx)», FARUA: Revista del Centro Virgitano de Estudios Históricos, 15 (2012), pp. 6I-74.

Calvo Salvador, Adelina; Susinos Rada, Teresa y García Lastra, Marta: «El largo camino hacia la coeducación: un análisis de las etapas de la educación de las mujeres a partir de tres relatos de vida escolar», Revista de Educación, 354 (2011), pp. 319-320.

Canales Serrano, Antonio Francisco: «Little intelectuals. Girls' academic secondary education under Francoism: Projects, realities and paradoxes», Gender and Education, 24, 4 (2012), pp. 375-39I.

Canales Serrano, Antonio Francisco: «El modelo de acceso femenino al Bachillerato de la Europa del sur», en Espigado Tocino, M. Gloria; Gómez Fernández, Juan; Pascua Sánchez, María José de la; Sánchez Villanueva, Juan Luis y Vázquez Domínguez, Carmen (eds.): La Constitución de Cádiz: genealogía y desarrollo del sistema educativo liberal, Cádiz, Universidad de Cádiz, 2013, pp. 589-596.

Canales Serrano, Antonio Francisco: «A baccalaureate programme for young ladies. Father Errandonea's proposal in the debate on female secondary education in Spain during the early years of Franco's regime», en Cagnolati, Antonella y Canales Serrano, Antonio Francisco (eds.): Women's Education in Southern Europe. Historical Perspectives (18401970), Roma, Aracne Editrice, 2017, pp. 237-260.

Canales Serrano, Antonio Francisco y Corrales, C.: «El campus que nunca fue», en AlCalá, P.; Corrales, C. y López, J. (coords.): Ni tontas, ni locas. Las intelectuales en el Madrid del primer tercio del siglo XX, Madrid, FECYT, 2009, pp. IO6-II7.

Cano González, Rufino: «Las escuelas de amiga: espacios femeninos de trabajo y educación de párvulos y de niñas», Aula: Revista de Pedagogía de la Universidad de Salamanca, i6 (20IO), pp. I55-I85.

Capel Martínez, Rosa María: «Mujer y educación en el Antiguo Régimen», Historia de la Educación: Revista Interuniversitaria, 26 (2007), pp. 85-IIо.

Capel Martínez, Rosa María: «La educación superior de las mujeres: logros y resistencias en el camino de la emancipación», en Aguilar Gavilán, Enrique (coord.): La Universidad de Córdoba en el centenario de la Junta para la Ampliación de Estudios, Córdoba, Editorial Universidad de Córdoba, 2008, pp. 19-42.

Capel Martínez, Rosa María y Magallón Portolés, Carmen: «Un sueño posible: la Jae y la incorporación de las españolas al mundo educativo y científico», en SÁnchez Ron, José Manuel; Lafuente, Antonio; Romero, Ana y Sánchez de Andrés, Leticia (eds.): El laboratorio de España: la Junta para Ampliación de Estudios e Investigaciones Científicas 1907-1939, Madrid, Residencia de Estudiantes-Ministerio de Cultura, 2007, pp. 223-249.

Carreño, Miryam y Rabazas Romero, Teresa: «Los manuales de Economía Doméstica: una preparación exigente para un trabajo no remunerado», en JuAn, Víctor (coord.): Museos pedagógicos: la memoria recuperada, Huesca, Museo Pedagógico de Aragón, 2008, pp. 337-350. 
Carreño, Miryam y Rabazas Romero, Teresa: «Sobre el trabajo de ama de casa. Reflexiones a partir del análisis de manuales de Economía doméstica», Revista Complutense de Educación, 2I, I (2010), pp. 55-72.

Casado Mejía, Rosa; Flecha García, Consuelo; Guil Bozal, Ana; Martínez Torres, M. ${ }^{a}$ del Rocío; Padilla Carmona, M. Teresa y Vázquez Bermúdez, Isabel: Aportaciones a la investigación sobre mujeres y género, Sevilla, @rea digital 2.o, S.L., 20I5, I407 pp.

Casals Bergés, Quintí: «Zoe Rosinach Pedrol», en Bayo, Emili (ed.): Lleida és femení: dones per a la historia, Lleida, Alfazeta, 2009, pp. I05-II3.

Casals Bergés, Quintí: «Dona, educación i ciència», en Vega, Eulàlia: Dones de Lleida: de la Restauració a la Guerra Civil, Lleida, Alfazeta, 20Io, pp. 57-89.

CASAls Bergés, Quintí: «Les primeres universitàries lleidatanes (I882-1920)», Shikar: revista del Centre d'Estudis Comarcals del Segrià, 3 (2016), pp. 64-78.

Casals Bergés, Quintí: «El acceso de las mujeres a la Universidad en España: el caso de las primeras universitarias leridanas (1882-1920)», Cuadernos del Instituto Antonio de Nebrija de Estudios sobre la Universidad. CIAN, 20, 2 (2017), pp. 275-30I.

Causapé Gracia, Belén: Pioneras del Derecho en Aragón: 19I0-1975. De las aulas universitarias a la profesionalización jurídica. Proceso de evolución e Historias de vida, tesis de doctorado, Universidad de Zaragoza (20I7).

Cenarro Lagunas, Ángela: «La Falange es un modo de ser (mujer): discursos e identidades de género en las publicaciones de la Sección Femenina (1938-1945)», Historia y Política: Ideas, Procesos y Movimientos Sociales, 37 (20I7), pp. 9I-I20.

Cid Galante, Rosa María: «As probas de exame para ocupar o posto de directora na Escola Normal de Mestras de Ourense: I880", Sarmiento: Anuario Galego de Historia da Educación, I8-I9 (2015), pp. 227-252.

Codina Canet, María Adelina y San Segundo, Rosa: «Fuentes Documentales y archivo de la Residencia de Señoritas de Madrid (1915-1936)", Revista General de Información y Documentación, 25, 2 (2015), pp. 493-515.

Collado Salguero, Isabel: «Walda y Ana María: maestras de maestras», Alborayque: Revista de la Biblioteca de Extremadura, 5 (20II), pp. 215-245.

Colmenar Orzaes, María del Carmen: «La institucionalización de la maternología en España durante la Segunda República y el franquismo», Historia de la Educación: Revista Interuniversitaria, 28 (2009), pp. I6I-I83.

Comas Rubí, Francesca y Miró Montoliu, María Isabel: «El Testimoni de Rosa Roig, un exemple de renovació pedagògica a les Escoles Normals del primer terç de segle XX», Educació i Història: Revista d'Història de l'Educació, I4 (2009), pp. 197-227.

Comella Gutiérrez, Beatriz: «Los Reales Colegios de Santa Isabel y Loreto de Madrid según sus Constituciones de 1715 y 1718», Historia de la Educación: Revista Interuniversitaria, 3I (20I2), pp. I67-I87.

Contu, Fabio: «Una mujer de cultura sin fronteras entre cristianismo y paganismo: Hipatia de Alejandría de Egipto», en Arriaga, M.; Cruzado, A.; González de Sande, M. y Ortiz DE ZÁRATE, A.: De lo sagrado y lo profano. Mujeres tras/entre/sin frontera, Sevilla, Arcibel editores, 2009, pp. 77-94.

Cortada Andreu, Esther: «D’alumna a mestra: l'accés de les dones al magisteri oficial», Educació $i$ història: Revista d'bistòria de l'educació, I7 (2011), pp. 47-75.

Cotelo Guerra, Dolores: «Una iniciativa pública de capacitación profesional femenina en el primer tercio del siglo xx: la Escuela del Hogar y Profesional de la Mujer de Madrid», Innovación Educativa, 26 (2016), pp. 59-75.

Cruz Rodríguez, María Alcázar y Sancho Rodríguez, María Isabel: «Las Escuelas Primarias de Jaén. Siglo xix. I. Las mujeres de la provincia de Jaén en la Primera Enseñanza. De los antecedentes a finales del siglo XIX», en Cabrera Espinosa, Manuel y López CordeRO, Juan Antonio (eds.): VII Congreso virtual sobre Historia de las Mujeres, 20I5, pp. I25-I78. 
UNA DÉCADA DE PUBLICACIONES SOBRE HISTORIA DE LA EDUCACIÓN

DE LAS MUJERES (2007-20I7)

CONSUELO FLECHA GARCÍA

Cuesta Bustillo, Josefina: «Mujeres en la Universidad Internacional Menéndez Pelayo bajo la dictadura de Franco: Una aproximación desde la perspectiva de género», en FolguerA, Pilar (coord.): Mujeres con voz. Voces desde el silencio. Una historia necesaria de la UIMP, Santander, UIMP, 20IO, pp. 235-302.

Cuesta Bustillo, Josefina: "Género, saber y trabajo. Mujeres y universidad en la España contemporánea», en VAl VAldivieso, María Isabel del y Martínez Quinteiro, Esther (eds.): Comiendo del fruto probibido: mujeres, ciencia y creación a través de la Historia, Barcelona, Icaria, 20I5a, pp. 137-190.

Cuesta Bustillo, Josefina: «Mujeres y enseñanza superior: problemas y procesos. España, del siglo xix al siglo XX», en Olivero Guidobono, Sandra y Caño Ortigosa, José Luis (coords.): Temas americanistas: historia y diversidad cultural, Sevilla, Universidad de Sevilla-Diputación, 2015b, pp. 785-796.

Cuesta, Josefina; Flecha, Consuelo; Matilla, M. Jesús; Prado, M. ${ }^{a}$ Luz de y Rodríguez Sofía: «Dificultades de las fuentes para el estudio de la historia de las mujeres en la universidad española», en Folguera, Pilar; Pereira Castañares, Juan Carlos; García García, Carmen; Izquierdo Martín, Jesús; Pallol Trigueros, Rubén; Sánchez García, Raquel; Sanz Díaz, Carlos y Toвoso Sánchez, Pilar (coords.): Pensar con la historia desde el siglo XXI: actas del XII Congreso de la Asociación de Historia Contemporánea, Madrid, Universidad Autónoma de Madrid, 20I5, pp. 869-887.

Cuesta, Josefina; Prado Herrera, María Luz de y Rodríguez, Francisco J. (dirs.): ¿ Mujeres sabias?: mujeres universitarias en España y América Latina, Limoges, PULIM (Presses Universitaires de Limoges), 2015, 507 pp.

Cuesta, Josefina; Turrión, María José y Merino, Rosa María (eds.): La Residencia de Señoritas y otras redes culturales femeninas, Salamanca, Ediciones Universidad de SalamancaMadrid, Fundación Ortega y Gasset-Gregorio Marañón, 2015a, 443 pp.

Cuesta, Josefina; Turrión, María José y Merino, Rosa María: «Dos residencias universitarias femeninas en España, I9I4-I9I5», en Cuesta, Josefina; Turrión, María José y Merino, Rosa María (eds.): La Residencia de Señoritas y otras redes culturales femeninas, Salamanca, Ediciones Universidad de Salamanca-Madrid, Fundación Ortega y Gasset-Gregorio Marañón, 20I5b, pp. II-32.

Cueva, Almudena de la: «No sólo como sino con el hombre: la Institución Libre de Enseñanza y la educación de la mujer», Revista de Occidente, Madrid, 4I3 (2015), pp. 5-19.

Cueva, Almudena de la y Márquez Padorno, Margarita (eds.): Mujeres en vanguardia: la Residencia de Señoritas en su centenario (I9I5-1936), Madrid, Publicaciones de la Residencia de Estudiantes, 2016, 399 pp.

Dalakoura, Katerina: «El género en la historiografía griega de educación (1970-20I2)», Espacio, Tiempo y Educación, 3, I (2016), pp. 363-38I.

Delgado Martínez, M. a Ángeles: Científicas y educadoras: las primeras mujeres en el proceso de la construcción de la Didáctica de las Ciencias de España, Murcia, Universidad, 2009, 370 pp.

Delgado Martínez, M. a Ángeles y López, J. Damián: «Maestras y profesoras del área de ciencias naturales en los focos de renovación pedagógica de las primeras décadas del siglo xx», en Sánchez Pascua, Felicidad; Alejo Montes, Francisco Javier; Calvo Población, Gaspar Félix; Lucero Fustes, Manuel; Oria Segura, María Rosa e Iglesias Verdegay, Enrique (coords.): Relaciones internacionales en la Historia de la Educación. Junta para Ampliación de Estudios e Investigaciones Cientificas (1907-2007), Cáceres, Universidad de Extremadura, 2007, pp. 93-106.

Díaz SÁnchez, Pilar: «Incorporación y presencia de las mujeres en los colegios profesionales españoles durante la Dictadura y la Transición», en Folguera, Pilar; Pereira CastaÑares, Juan Carlos; García García, Carmen; Izquierdo Martín, Jesús; Pallol Trigueros, Rubén; Sánchez García, Raquel; Sanz Díaz, Carlos y Toboso Sánchez, Pilar 
(coords.): Pensar con la historia desde el siglo XXI: actas del XII Congreso de la Asociación de Historia Contemporánea, Madrid, Universidad Autónoma de Madrid, 20I5, pp. IIos-II24.

Diego Pérez, Carmen y González Fernández, Montserrat: «Mujeres enseñando a mujeres: la formación de maestras parvulistas», en Celada Perandones, Pablo (ed.): Arte y oficio de enseñar: dos siglos de perspectiva histórica, XVI Coloquio Nacional de Historia de la Educación, El Burgo de Osma, Soria, vol. 2, 2011, pp. 529-538.

Domenech Jiménez, M. ${ }^{a}$ Isabel: Las maestras de la guerra civil y el primer franquismo en la provincia de Alicante, tesis de doctorado, Universidad de Alicante (2016).

Domínguez Cabrejas, María Rosa: Cien años de libre acceso de las mujeres a la Universidad, Zaragoza, Prensas Universitarias, 20I0, 79 pp.

Duch Plana, Monserrat y Palau Vergés, Montserrat: «La socialización de los saberes femeninos: El Instituto de Cultura y Biblioteca Popular para la Mujer, Barcelona (I900-1936)», Historia Social, 82 (2015), pp. I33-I47.

Espigado Tocino, M. Gloria: «La mujer en el reinado de Isabel II: Educación, consideración social y jurídica», en Quesada NiETO, Dolores (coord.): Isabel II y la mujer en el siglo XIX, Madrid, Ministerio de Educación Cultura y Deporte, 2010, pp. II3-I54.

Espino Martín, Javier: «La pedagogía jesuita de las “religiosas” entre los siglos XVI y xIX: de las Ursulinas a la Sociedad del Sacré Cœur», Sincronía, 72 (2017), pp. 308-327.

Ezama GIL, María de los Ángeles: La educación de la mujer a comienzos del siglo xx: el Centro Iberoamericano de Cultura Popular Femenina (I906-1926), Málaga, Universidad de Málaga, 2017, $189 \mathrm{pp}$.

FERnÁndez Fernández, Idoia: «Género, educación activa, lengua y nación en el País Vasco: Julene Azpeitia (I888-1980), exponente de una educación vasca en ciernes», Historia de la Educación: Revista Interuniversitaria, 3I (20I2), pp. 275-297.

Ferrer Valero, Sandra: «Mujeres e Historia, Mujeres eruditas en la corte de Isabel la Católica», Clío: Revista de Historia, 184 (2017), pp. 62-67.

Flecha García, Consuelo: «Historiografía sobre educación de las mujeres en España», en Val, M. ${ }^{a}$ Isabel del; Santo Tomás, Magdalena; Dueñas, M. Jesús y Rosa, Cristiana de la (coords.): La historia de las mujeres: una revisión historiográfica, Valladolid, Secretariado de Publicaciones Universidad de Valladolid, 2004, pp. 335-353.

Flecha García, Consuelo (coord.): «Historia de la educación de las mujeres», Historia de la Educación: Revista Interuniversitaria, 26 (2007a), 251 pp.

Flecha García, Consuelo: "Historia y genealogía en la educación de las mujeres», Historia de la Educación: Revista Interuniversitaria, 26 (2007b), pp. 27-37.

Flecha García, Consuelo: «A "perspectiva de xénero" na formación do profesorado universitario», en Fariña, M. ${ }^{a}$ Jesús; Mayobre, Purificación y SuÁrez, Beatriz: O reto da igualdade. Feminismo, Xénero, Universidade, Vigo, Editorial Galaxia, 2007c, pp. 65-84.

Flecha García, Consuelo: «La investigación en Estudios de las Mujeres en Andalucía», Revista Fuentes, 7 (2007d), pp. 79-90.

Flecha García, Consuelo: «Educar o instruir en los proyectos de formación para las mujeres», en Actas de las VI Jornadas de Historia de Estepa: La Educación en el Siglo XIX, Estepa, Ayuntamiento de Estepa. Delegación de Patrimonio, 2007e, pp. I25-I40.

Flecha García, Consuelo: "O acesso das mulheres à docência nos institutos de ensino secundário, em Espanha», Revista Lusófona de Educação, 2 (2008), pp. 97-II2.

Flecha García, Consuelo: «Mujeres y ciencia en la propuesta de Pedro Poveda», en Doctor Buenaventura Delgado Criado. Pedagogo e Historiador, Barcelona, Publs. Universidad de Barcelona, 2009a, pp. 547-564.

Flecha García, Consuelo: «Igualdad y Estudios de las Mujeres en las Universidades. Contexto legislativo", en vv. AA.: Historia de la Educación de las Mujeres, Murcia, Sociedad Española de Historia de la Educación, 2009b, pp. II-3I. 
Flecha García, Consuelo: «La contribución de la escuela católica a la formación femenina», Canelobre, 54, 2009c, pp. 46-63.

Flecha García, Consuelo: «Between Modernization and Conservatism: Spain», en AlbiseTTI, James; Goodman, Joyce y Rogers, Rebecca (eds.): Girls' Secondary Education In The Western World, New York, Palgrave Macmillan, 2010a, pp. 77-92.

Flecha García, Consuelo: «La mujer en el magisterio», Tavira. Revista de Ciencias de la Educación, 26 (2010b), pp. 273-295.

Flecha García, Consuelo: «Compartiendo saberes y experiencia en la Universidad Internacional de Santander», en Folguera, Pilar (ed.): Mujeres con voz. Voces del silencio. Una historia necesaria de la UIMP, Santander, UIMP, 20IOc, pp. 69-I25.

Flecha García, Consuelo: «Las aspirantes al magisterio secundario en el proyecto de renovación pedagógica de la JAE», en Sánchez Ron, José Manuel y García-Velasco, José: 100 JAE. La Junta para Ampliación de Estudios e Investigaciones Cientificas en su centenario, Madrid, Publicaciones de la Residencia de Estudiantes, vol. 2, 2orod, pp. 649-68I.

Flecha García, Consuelo: «Los Estudios de las Mujeres», en Amador Muñoz, Luis y MonReal Gimeno, M. ${ }^{a}$ Carmen: Intervención social y género, Madrid, Narcea, 20ioe, pp. 15-39.

Flecha García, Consuelo: «Profesoras en la Universidad, el tránsito de las pioneras en España», Arenal: Revista de Historia de Mujeres, 17, 2 (2010f), pp. 255-297.

Flecha García, Consuelo: «Por Derecho Propio. Universitarias y Profesionales en España en torno a 1910», Tabanque. Revista Pedagógica, 24 (2011), pp. I57-I74.

Flecha García, Consuelo: «La Segunda República, las mujeres y la educación», en Sánchez de Madariaga, Elena (ed.): Las maestras de la República, Madrid, Los Libros de la Catarata, 2012a, pp. 23-53.

Flecha García, Consuelo: «Profesoras de Historia Medieval: mirando a los orígenes», en DíAz, Pilar: Impulsando la historia desde la historia de las mujeres, Huelva, Publs. Universidad de Huelva, 20I2b, pp. Ios-IIs.

Flecha García, Consuelo: «Políticas y espacios para mujeres en el origen y desarrollo del sistema educativo español», Bordón, 65, 4 (2013a), pp. 75-89.

Flecha García, Consuelo: «Mujeres en la tradición cultural de occidente», en Galcerán, Mar y Vilanou, Conrad (eds.): Dones i pedagogía, Barcelona, Ed. Claret, 20izb, pp. II-39.

Flecha García, Consuelo: «Ganando espacios en la universidad española en la primera mitad del siglo xx», en Val Valdivieso, María Isabel del y Martínez Quinteiro, Esther (eds.): Comiendo del fruto probibido: mujeres, ciencia y creación a través de la Historia, Barcelona, Icaria, 2015a, pp. I03-135.

Flecha García, Consuelo: «Itinerarios académicos de mujeres en la universidad española», en Cuesta, Josefina; De Prado, María Luz y Rodríguez, Francisco J.: ¿ Mujeres sabias? Mujeres universitarias en España y América Latina, Limoges, Pulim (Presses Universitaires de Limoges), 2015b, pp. 57-8r.

Flecha García, Consuelo: "Alumnas y equipos directivos de la Residencia Teresiana de Madrid», en Cuesta, Josefina; Turrión, María José y Merino, Rosa María (eds.): La Residencia de Señoritas y otras redes culturales femeninas, Salamanca, Ediciones Universidad de Salamanca-Madrid, Fundación Ortega y Gasset-Gregorio Marañón, 20I5c, pp. 287-312.

Flecha García, Consuelo: «Ilusiones de mujeres. A propósito de las alumbradas y su magisterio», en Medina Arjona, Encarnación y Gómez Moreno, Paz: Escritura y vida cotidiana de las mujeres de los siglos XVI y XVII (Contexto mediterráneo), Sevilla, Alfar, 20I5d, pp. I43-I66.

Flecha García, Consuelo: «La Educación Franquista y las Mujeres», en Canales Serrano, Antonio y Gómez Rodríguez, Amparo (eds.): La larga noche de la educación española. El sistema educativo español en la posguerra, Madrid, Biblioteca Nueva, 20I5e, pp. 22I-255. 
Flecha García, Consuelo: «Memoria de mujeres pioneras: universitarias en Andalucía», en Lemus López, Encarnación: Renovación en las aulas. La Institución Libre de Enseñanza en Andalucía, Sevilla, Centro de Estudios Andaluces, 2016, pp. 67-92.

Flecha, Consuelo y Capel, Rosa María: «Panorama de la educación femenina en España», en Alcalá Cortijo, Paloma y otras: Ni tontas ni locas. Las intelectuales en el Madrid del primer tercio de siglo, Madrid, FECYT, 2009, pp. 66-79.

Flecha, Consuelo y Palermo, Alicia Itatí (coords.): Mujeres y Universidad en España y en América Latina, Buenos Aires, Miño y Dávila Edits., 2008, 238 pp.

Folguera, Pilar (coord.): Mujeres con voz. Voces desde el silencio. Una historia necesaria de la UIMP, Santander, UIMP, 20IO, $355 \mathrm{pp}$.

FORT, Ester de: «Maestras y maestros en Italia desde el fin del Antiguo Régimen hasta el ascenso del Fascismo", Historia y Memoria de la Educación, I (20I5), pp. I3I-20I.

Frax Rosales, Esperanza y Matilla Quiza, María Jesús: «La enseñanza de la sumisión. La escuela de niñas en el primer franquismo», en Pérez Cantó, María Pilar (coord.): El origen bistórico de la violencia contra las mujeres, Madrid, Dilema, 2009, pp. 371-428.

Gabriel Fernández, Narciso de: «A educación das mulleres no século xix: exclusión, dependencia e autonomía», Sarmiento: Anuario Galego de Historia da Educación, I7 (2013), pp. 7-35.

Gabriel Fernández, Narciso de: "The entrance of women into the teaching profession in Spain (1855-1940)", History of Education, 43, 3 (2014), pp. 334-354.

GaItÁn Salinas, Carmen: «Arte, educación y mujer. Embarque hacia el exilio de 1939", Archivo Español de Arte, 89, 353 (2016), pp. 6I-76.

Gallego Pareja, Manuel: «La Segunda Enseñanza de las niñas en Castro Urdiales a mitad del siglo XIX», Cabás, Io (2013), pp. 79-IOI.

GÁlvez Méndez, Victoria Elizabeth: Epistemología, mujeres y ciencia. Una historia del devenir de subjetividades, tesis de doctorado, Universidad de Granada (2016).

García Álvarez, Betsabé: Juguen dames: les primeres universitàries: Helena Maseras, Dolors Aleu i Martina Castells, Badalona, Ara Llibres, 20Iо, 20I pp.

García Cabeza, Belén: «A educación das mulleres no pensamento feminista galego de finais do xIx e comezos do xx: a perspectiva de Emilia Pardo Bazán», Sarmiento: Anuario Galego de Historia da Educación, I4 (2010), pp. 109-123.

García Colmenares, Carmen: Las primeras psicólogas españolas: itinerarios vitales y profesionales, Granada, Editorial Universidad de Granada, 20II, 136 pp.

García Colmenares, Carmen: «Educar en tiempos de guerra. Maestras y psicólogas republicanas en las colonias escolares», en SÁnchez de Madariaga, Elena (ed.): Las maestras de la República, Madrid, Los Libros de la Catarata, 2012, pp. Iо6-I2I.

García Fernández, Miguel: «Alfabetización, autoría y producción impresa. Una aproximación en femenino a la cultura letrada de Galicia moderna», Revista Cuadernos de Estudios Gallegos, 59, I25 (2012), pp. 193-232.

García Galán, Sonia: Mujeres entre la casa y la calle. Educación, feminismos y participación politica en Asturias, 1900-193I, Oviedo, Trabe, 2015, $394 \mathrm{pp}$.

García Gil, Carmen; Flecha, Consuelo; Cala, María Jesús; Núñez, Marina; Guil, Ana; Martínez, Rocío y VázQuez, Isabel (eds.): Mujeres e investigación. Aportaciones interdisciplinares, Sevilla, @rea digital 2.o s.L., 2016, 803 pp.

García Gil, Desirée: «Mujer, Educación y Conservatorio: un relato de vida», Dedica. Revista de Educação e Humanidades, I2 (2017), pp. I7I-190.

García Gil, Desirée y Pérez Colodrero, Consuelo: «Mujer y educación musical (escuela, conservatorio y universidad): dos historias de vida en la encrucijada del siglo xx español», Dedica. Revista de Educação e Humanidades, 6 (20I4a), pp. I7I-I86.

García Gil, Desirée y Pérez Colodrero, Consuelo: «Mujer y educación musical (escuela, conservatorio, universidad): dos historias de vida en la encrucijada del siglo XX», en SAdIO 
Ramos, Fernando José y Ortiz Molina, María Angustias (coord.): Identidades culturales: Educación, Artes y Humanidades, Ceuta, Fernando Ramos, 20I4b, pp. 87-88.

García Gil, Desirée y Pérez Colodrero, Consuelo: «Educación musical femenina en el Madrid del siglo XIX, algunos apuntes sobre la asociación para la enseñanza para la mujer (1870-1900)», Dedica. Revista de Educação e Humanidades, 9 (2016), pp. 91-105.

García Gil, Desirée y Pérez Colodrero, Consuelo: «Música, educación e ideología por y para Mujeres de la Sección Femenina a través de los contenidos de Y. Revista de la mujer nacionalsindicalista y Medina (1938-1946)», Historia y Comunicación Social, 22, I (2017), pp. I23-I39.

García Perales, Nuria y Martín Sánchez, Miguel Ángel: «Más de quinientas “almas”: el acceso a la educación de la mujer en el sistema educativo liberal», en Espigado Tocino, M. Gloria; Gómez Fernández, Juan; Pascua Sánchez, María José de la; Sánchez Villanueva, Juan Luis y Vázquez Domínguez, Carmen (eds.): La Constitución de Cádiz: genealogía y desarrollo del sistema educativo liberal, Cádiz, Universidad de Cádiz, 2013, pp. 637-646.

García Pérez, Noelia: «Las voces del Humanismo y la Educación de la mujer en el Renacimiento: entre el pro-feminismo y la misoginia», en Arriaga, Mercedes; Cruzado, Ángeles y OrTIZ de ZÁrate, Amalia (ed.): Feminismo e interculturalidad, Sevilla, Arcibel, 2008, pp. I45-I57.

García Pérez, Noelia: «El acceso de la mujer a la "alta cultura” en la Europa del Renacimiento", Arbor: Ciencia, Pensamiento y Cultura, 760 (2013), 9 pp. (Recurso electrónico, archivo digital).

García Romero, Juana: «Las conferencias dominicales en la Asociación para la Enseñanza de la Mujer», Cabás, ıо (2013), pp. Iо2-го8.

García SuÁrez, Pedro: «Mujer, lectura y educación en la obra de Emilia Pardo Bazán», Hispanic Research Journal: Iberian and Latin American Studies, I8, 6 (2017), pp. 466-478.

GÁRriz YAGÜE, María Rosario: «Las maestras de escuela de niñas en Navarra durante el Antiguo Régimen», Principe de Viana, 72, 254 (2011), pp. 465-482.

Gimenez Salinas i Colomer, Esther: «Dones a la universitat: cent anys de prohibicions», en Miquel i Martí, Victòria: DOCTES, doctores i catedrátiques: cent any d'accès lliure de la dona a la Universitat, Barcelona, Generalitat de Catalunya, Consell Interuniversitari de Catalunya, 2010, pp. 69-84.

Giró Miranda, Joaquín: Mujer y educación. Las maestras: un análisis sobre la identidad de género y trabajo, Logroño, Instituto de Estudios Riojanos: Ayuntamiento de Logroño, 2009, $308 \mathrm{pp}$.

GleICHAUF, Ingeborg: Mujeres filósofas en la historia: desde la antigüedad hasta el siglo XXI, Barcelona, Icaria, 2010, I59 pp.

Gómez Cuesta, Cristina: «Mujeres y leyes: las estudiantes de Derecho en la Segunda República», en Folguera, Pilar; Pereira Castañares, Juan Carlos; García García, Carmen; Izquierdo Martín, Jesús; Pallol Trigueros, Rubén; Sánchez García, Raquel; Sanz Díaz, Carlos y Tовоso Sánchez, Pilar (coords.): Pensar con la historia desde el siglo XXI: actas del XII Congreso de la Asociación de Historia Contemporánea, Madrid, Universidad Autónoma de Madrid, 2015, pp. 1005-1024.

Gómez García, Mercedes: La educación física de la mujer de Salamanca: aportaciones históricas, tesis de doctorado, Universidad de Salamanca (2016).

Gómez Gómez, M. ${ }^{a}$ Carmen: La Grande Obra de Atocha: ideario pedagógico, realizaciones escolares y promoción femenina, tesis de doctorado, Universidad Pontificia de Salamanca (2015).

Gómez Gómez, M. ${ }^{a}$ Carmen; Escudero Vidal, Jacinto e Iglesias, M. ${ }^{a}$ Teresa: «La Universidad Popular Femenina de La Grande Obra de Atocha de A Coruña (1927-1968)», Cabás, I6 (2016), pp. 48-59.

Gómez SAN Miguel, Eva: Inspectoras de enseñanza primaria en el segundo tercio del siglo XX, tesis de doctorado, Universidad Complutense de Madrid (2016). 
González Barrero, Nuria: «El Colegio de La Paz y su papel en la educación de las mujeres en el Madrid del Antiguo Régimen (1740-1780)», Espacio, Tiempo y Educación, 4, 2 (2017), pp. 287-306.

GonzÁlez Gómez, Sara y PAYÁ Rico, Andrés: «Ciencia y género: Investigadoras en formación a finales del franquismo", Feminismo/s, 29 (2017), pp. 173-200.

GonzÁlez PéRez, Teresa: Mujeres, historia y educación: algunos datos sobre Canarias, Las Palmas de Gran Canaria, Anroart Ediciones, 2007, 4I4 pp.

GonzÁlez Pérez, Teresa: «El aprendizaje de la maternidad: discursos para la educación de las mujeres en España (siglo xx)», Revista de Ciencias Sociales, 46 (2008a), pp. 9I-II7.

González Pérez, Teresa: La voz del olvido: maestras de ayer, Las Palmas de Gran Canaria, Anroart, 2008b, 290 pp.

GonzÁlez PÉrez, Teresa: «Aprender a enseñar en el siglo xix. La formación inicial de las maestras españolas», Revista Electrónica Interuniversitaria de Formación del Profesorado, I3, 4 (2010a), pp. I33-I44.

González PÉREz, Teresa: «Mujeres, educación y democracia», Revista de Educación, 35I (20Iob), pp. 337-359.

GonzÁlez Pérez, Teresa: «Educación y fronteras. María Sánchez Arbós y su lucha por la renovación pedagógica en Canarias (1920-1925)», Revista de Educación, 356 (2011a), pp. 431-455.

González PéRez, Teresa: «Las Primeras alumnas en los estudios de bachillerato en Canarias», Educació i història: Revista d'història de l'educació, I7 (20IIb), pp. IOI-I32.

González Pérez, Teresa: «La conquista de espacios del saber. Mujeres universitarias en Canarias durante la primera mitad del siglo xx», en Hernández Díaz, José María (coord.): Formación de élites y educación superior en Iberoamérica: (ss. XVI-XXI), vol. I, 20I2a, pp. 543-554.

GonzÁlez Pérez, Teresa: «Modernitat i tradició: el procés d'escolarització en l'ambit cultural europeu i la inserció educativa de les nenes», Temps d'educació, 43 (2012b), pp. I45-166.

GonzÁlez PÉREz, Teresa: «Educación y transformación social: el proyecto educativo para las mujeres en el imaginario anarquista», História da Educação, 17, 39 (2013), pp. 213-230.

González Pérez, Teresa: «Dios, patria y hogar. La trilogía en la educación de las mujeres», Hispania Sacra, 66, I33 (2014a), pp. 337-363.

GonzÁlez PÉrez, Teresa: «Maestras españolas en el franquismo: protagonistas olvidadas», REXE: Revista de Estudios y Experiencias en Educación, I3, 25 (20I4b), pp. I07-I24.

GonzÁlez SAnz, Alba: «La memoria de la educación en las autobiografías de autoras españolas de preguerra (1900-1936)», Archivum: Revista de la Facultad de Filología, tomo 6I-62 (2OII-2OI2), pp. I79-2I4.

Grana GiL, Isabel: «La historia de la educación de las mujeres en España: líneas actuales de investigación», Revista de Educación, 334 (2004), pp. I3I-I42.

Grana GIL, Isabel: «Las mujeres y la segunda enseñanza durante el franquismo», Revista de Historia de la Educación: Revista Interuniversitaria, 26 (2007), 251 pp.

Grana GIL, Isabel: «La depuración de las profesoras de Instituto en Cataluña durante el franquismo", Annals del Patronat d'Estudis Històrics d'Olot i Comarca, 2I (2010), pp. 235-250.

Grana Gil, Isabel y Alonso Briales, Mariana: «La educación de las mujeres en Andalucía durante el franquismo a través de las historias de vida», en Berruezo Albéniz, María Reyes y Conejero López, Susana (coords.): El largo camino hacia una educación inclusiva: la educación especial y social del siglo XIX a nuestros dias, Pamplona-Iruñea, vol. 2, 2009, pp. IOI-II2.

Grana Gil, Isabel y Martín ZúÑIga, Francisco: «Las profesoras durante el franquismo: freno a la vanguardia intelectual de las mujeres», Bordón, 68, 3 (2016), pp. 59-7I.

Grana Gil, Isabel y Rabazas Romero, Teresa: «Reflexiones en torno al programa de la Historia de la Educación de las mujeres», en vv. AA.: Historia de la Educación de las Mujeres, Murcia, Sociedad Española de Historia de la Educación, 2009, pp. 45-6o. 
Groves, Tamar Rachel; López, Santiago y Gutiérrez Palmero, María José: «El último impulso: la consolidación de las carreras científicas de las mujeres en las Facultades de Medicina de Castilla y León entre el tardofranquismo y la transición democrática», en CuESTA, Josefina; De Prado, María Luz y Rodríguez, Francisco J.: ¿ Mujeres sabias? Mujeres universitarias en España y América Latina, Limoges, Pulim (Presses Universitaires de Limoges), 2015, pp. 335-372.

Guardia Herrero, Carmen de la: «Maestras republicanas españolas en el exilio», en Sánchez de Madariaga, Elena (ed.): Las maestras de la República, Madrid, Los Libros de la Catarata, 20I2, pp. I84-235.

Guichot Reina, Virginia: «La educación de la mujer de fines del siglo xix a través de la prensa femenina: La Madre de Familia», en Espigado Tocino, M. Gloria; Gómez Fernández, Juan; Pascua Sánchez, María José de la; Sánchez Villanueva, Juan Luis y Vázquez Domínguez, Carmen (eds.): La Constitución de Cádiz: genealogía y desarrollo del sistema educativo liberal, Cádiz, Universidad de Cádiz, 20ı3, pp. 647-656.

Guil Bozal, Ana: "Genealogía de psicólogas españolas en Latinoamérica», Clepsydra: Revista de Estudios de Género y Teoría Feminista, n. ${ }^{\circ}$ Extra is (2016), pp. 63-76.

Guil Bozal, Ana y Flecha García, Consuelo: «Universitarias en España: De los inicios a la actualidad», Historia de la Educación Latinoamericana, I7, 24 (2015), pp. I25-I48.

Guil Bozal, Ana y Vera Gil, Sara: «Amanda Labarca, pionera de la educación y la política de las mujeres en Chile», Historia de la Educación Colombiana, 3, I3 (2010), pp. I43-159.

Guil Bozal, Ana y Vera Gil, Sara: «Mercedes Rodrigo, psicopedagoga pionera», en Olivero Guidobono, Sandra y Caño Ortigosa, José Luis (coords.): Temas americanistas: historia y diversidad cultural, 2015, pp. 817-826.

Gurrera Lluch, Monserrat: «L'educació de les dones en la primera escola nocturna i dominical de Mataró (1858-1868)», Annals del Patronat d'Estudis Històrics d'Olot i Comarca, 2I (2010), pp. 55-75.

Gutiérrez Pérez, Carmen María: «La maestra Blasa Barranco Cazalla y la escuela de niñas de Jamilena a finales del siglo XIX e inicios del XX», Trastámara, Revista de Ciencias Auxiliares de la Historia, 5 (2010a), pp. 43-53.

Gutiérrez Pérez, Carmen María: «Las escuelas públicas femeninas giennenses a principios del siglo xx: Los casos de Martos y Jamilena», Trastámara, Revista de Ciencias Auxiliares de la Historia, 6 (2010b), pp. 5-I4.

Gutiérrez San Miguel, Begoña: «Porque te vi llorar o la educación sentimental de la España de la postguerra", Arenal: Revista de Historia de Mujeres, 23, 2 (2016), pp. 247-266.

Hernández Andreu, Joan y Araque Hontangas, Natividad: «Pilar Díez y Jiménez-Castellanos: primera catedrático de Instituto de Lengua y Literatura Española», Pecia Complutense: Boletín de la Biblioteca Histórica Marqués de Valdecilla, 24 (2016), pp. 20-44.

Hernández Díaz, José María: «Alice Pestana, educadora portuguesa republicana en la Institución Libre de Enseñanza», Historia de la Educación: Revista Interuniversitaria, 3I (20I2), pp. 257-273.

Hernández Gómez, Carol Andrea: «Ideal de mujer virtuosa. Instruida, sencilla, señora de la casa, pozo de dulzura y abnegación: rastreos sobre la educación de la mujer a finales del siglo XIX y principios del siglo XX", Nodos y Nudos: Revista de la Red de Calificación de Educadores, 4, 37 (2014), pp. 65-74.

Herrero, Sara: «Docentes y referentes: María Goyri (1873-1954)», Revista de Occidente, Madrid, $4 \mathrm{I3}$ (2015), pp. 44-54.

Huguet SAntos, Montserrat: «Tradición misional y legado de las educadoras estadounidenses en España», en Cuesta, Josefina; Turrión, María José y Merino, Rosa María (eds.): La Residencia de Señoritas y otras redes culturales femeninas, Salamanca, Ediciones Universidad de Salamanca-Madrid, Fundación Ortega y Gasset-Gregorio Marañón, 2015, pp. 7I-II6. 
IвÁñez Domingo, Mélanie: «¿Alguien hablará de nosotras cuando hayamos muerto? Sobre género, franquismo y didáctica», Didácticas Específicas, I4 (2016), pp. 50-70.

Jiménez Morales, Rosario: «Pequeños defectos que debemos corregir: aprendiendo a ser mujer en la historieta sentimental de los años cincuenta y sesenta», Arbor: Ciencia, Pensamiento y Cultura, Extra 2 (20II), pp. I59-I68.

Jimeno, Concepción: «María Sánchez Arbós (1889-1976): el exilio interior de una maestra», Iber. Didáctica de las Ciencias Sociales, Geografía e Historia, 62 (2009), pp. 46-55.

Juan Castrillo, Albano de: «Las primeras mujeres médicas palentinas», en Cuesta, Josefina; Turrión, María José y Merino, Rosa María (eds.): La Residencia de Señoritas y otras redes culturales femeninas, Salamanca, Ediciones Universidad de Salamanca-Madrid, Fundación Ortega y Gasset-Gregorio Marañón, 2015, pp. 339-360.

Lafoz Rabaza, Herminio: «Maestras socialistas en la guerra civil. El caso de Aragón», en Sánchez de Madariaga, Elena (ed.): Las maestras de la República, Madrid, Los Libros de la Catarata, 20I2, pp. I22-I46.

Ledesma Pedraz, Manuela; Peinado Rodríguez, Matilde; Sancho Rodríguez, María Isabel; García Luque, Antonia y Rueda Parras, Carmen (coords.): Homenaje a Carmen de Michelena, Jaén, Universidad de Jaén, Servicio de Publicaciones, 20I4, 288 pp.

Lemus López, Encarnación: «La residencia de Señoritas. Las estudiantes andaluzas y el espíritu de la Residencia», en Lemus López, Encarnación: Renovación en las aulas. La Institución Libre de Enseñanza en Andalucía, Sevilla, Centro de Estudios Andaluces, 20I6, pp. I27-I47.

López Cordón Cortezo, María Victoria: «Reinas madres, reinas hijas: educación, política y correspondencia en las cortes dieciochescas», Historia y Política: Ideas, Procesos y Movimientos Sociales, 3I (20I4), pp. 49-80.

Lorenzo Arribas, Josemi: «La educación en la Europa altomedieval cristiana: nueve reflexiones con alguna polémica», Historia de la Educación. Revista Interuniversitaria, 26 (2007), pp. 39-63.

Magallón Portolés, Carmen: «El Laboratorio Foster de la Residencia de Señoritas. Las relaciones de la JAE con el International Institute for Girls in Spain, y la formación de las jóvenes científicas española», Asclepio. Revista de Historia de la Medicina y de la Ciencia, 59, 2 (2007), pp. 37-62.

Magallón Portolés, Carmen: «Las mujeres que abrieron los espacios de las ciencias experimentales para las mujeres, en la España del primer tercio del siglo xx», Arenal: Revista de Historia de Mujeres, 17, 2 (2010), pp. 319-347.

Magallón Portolés, Carmen: «Físicas, químicas y biólogas en el primer tercio del siglo xx: redes internacionales de apoyo. El laboratorio Foster de la Residencia de Señoritas», en Cuesta, Josefina; Turrión, María José y Merino, Rosa María (eds.): La Residencia de Señoritas y otras redes culturales femeninas, Salamanca, Ediciones Universidad de SalamancaMadrid, Fundación Ortega y Gasset-Gregorio Marañón, 2015, pp. 33-70.

Mandado Gutiérrez, Ramón Emilio; Sánchez-Gey Venegas, Juana y Madariaga de la CAMPA, Benito: La Institución Libre de Enseñanza y la Asociación para la Enseñanza de la Mujer. Bosquejo sobre la educación española del siglo XIX, Santander, Universidad Internacional Menéndez Pelayo, 20II, 200 pp.

Manrique Arribas, Juan Carlos: La mujer y la educación física durante el franquismo, Valladolid, Universidad, Secretariado de Publicaciones e Intercambio Editorial, 2008, 339 pp.

Manrique Arribas, Juan Carlos; López Pastor, Víctor Manuel; Torrego Egido, Luis y Mongas Aguado, Roberto: «La labor formativa desarrollada por la Sección Femenina de la Falange en la preparación de los mandos e instructoras durante el periodo franquista», Historia de la Educación: Revista Interuniversitaria, 27 (2008), pp. 347-365.

Mariño Costales, Mariam: "Movemento feminista e educación en Galiza: 1970-1990", Sarmiento: Anuario Galego de Historia da Educación, 17 (2013), pp. 37-53. 
UNA DÉCADA DE PUBLICACIONES SOBRE HISTORIA DE LA EDUCACIÓN

DE LAS MUJERES (2007-20I7)

CONSUELO FLECHA GARCÍA

Márquez Padorno, Margarita: «The Eight Sister. La relación del International Institute y la Junta para la Ampliación de Estudios en el avance de la coeducación universitaria en España», en Cuesta, Josefina; Turrión, María José y Merino, Rosa María (eds.): La Residencia de Señoritas y otras redes culturales femeninas, Salamanca, Ediciones Universidad de Salamanca-Madrid, Fundación Ortega y Gasset-Gregorio Marañón, 2015, pp. II7-130.

Martínez, Nazaret y Bedmar Moreno, Matías: «Vivencias educativas durante la Época Franquista en Zújar», Revista de Paz y Conflictos, 9, I (20I6), pp. 237-259.

Martínez Cuesta, Francisco Javier y Alfonso Sánchez, José Manuel: «Tardes de enseñanza y parroquia: el adoctrinamiento de las niñas en la España franquista a través de las revistas "Bazar” y “Tin Tan” (1947-1957)», El Futuro del Pasado: Revista Electrónica de Historia, 4 (2013), pp. 227-253.

Martorell, Manuel: «Hermanas Úriz. Dos pedagogas navarras en el "maquis español”», Revista: Gerónimo de Uztariz, 30-3I (2014-2015), pp. 39-58.

Matilla Quiza, María Jesús: «Las primeras doctoras universitarias en España. La Facultad de Filosofía y Letras de Madrid (1882-1954)», en Cuesta, Josefina; De Prado, María Luz y Rodríguez, Francisco J.: ¿ Mujeres sabias? Mujeres universitarias en España y América Latina, Limoges, Pulim (Presses Universitaires de Limoges), 2015, pp. 83-I22.

Matilla Quiza, María Jesús y Mó Romero, Esperanza: «De la excepción a la normalidad: Mujeres científicas en la Historia», Encuentros Multidisciplinares, I6, 47 (2014), pp. 2-II.

Meavilla Seguí, Vicente y Oller Marcén, Antonio Miguel: «La formación de maestros y maestras elementales en España a finales del siglo xix. El caso de la Geometría», Contextos Educativos: Revista de Educación, Extra i (2016), pp. 79-96.

Méndez, Josefina: Formación profesional de las mujeres en las escuelas de la Matritense: un proyecto político-económico en la España ilustrada, Oviedo, Editorial Trabe, 2017, 266 pp.

Merino Acebes, Azucena (coord.): Mujeres y educación durante el franquismo en imágenes: la Sección Femenina y el Auxilio Social (1934-1977), Madrid, Ed. Espuela de Plata, 2010, 190 pp.

Merino Hernández, Rosa María: "Presencia y ausencia de las mujeres científicas de la Segunda República en “ABC” y otras fuentes periodísticas», en Cuesta, Josefina; De Prado, María Luz y RodríGuez, Francisco J.: ¿ Mujeres sabias? Mujeres universitarias en España y América Latina, Limoges, Pulim (Presses Universitaires de Limoges), 20I5, pp. 225-24I.

Miquel i MARTí, Victòria et al.: DOCTES, doctores $i$ catedrátiques: cent any d'accès lliure de la dona a la Universitat, Barcelona, Generalitat de Catalunya, Consell Interuniversitari de Catalunya, 20I0, I80 pp.

Miqueo Miqueo, Consuelo: «Seducidas por la ciencia. La integración de las mujeres en la Facultad de Medicina de la Universidad de Zaragoza durante el siglo XX», en CuEsta, Josefina; Turrión, María José y Merino, Rosa María (eds.): La Residencia de Señoritas y otras redes culturales femeninas, Salamanca, Ediciones Universidad de Salamanca-Madrid, Fundación Ortega y Gasset-Gregorio Marañón, 2015, pp. 36I-406.

Molina Puertos, Isabel: La ficción doméstica: Ángela Grassi, Pilar Sinués y Faustina Sáez. Una aproximación a las imágenes de género en la España burguesa, tesis de doctorado, Universitat de València (2016).

Montero Díaz, Mercedes: La conquista del espacio público: mujeres españolas en la universidad (19I0-1936), Madrid, Minerva, 2009, $282 \mathrm{pp}$.

Montero Díaz, Mercedes: «Los primeros pasos hacia la igualdad: mujer y universidad en España (I9IO-1936)», Historia Crítica, 40 (20I0a), pp. I48-ı68.

Montero Díaz, Mercedes: «Los comienzos de la labor del Opus Dei con universitarias: la Residencia Zurbarán de Madrid (1947-1950)», Studia et Documenta: rivista dell'Istituto Storico San Josemaría Escrivá, 4 (2010b), pp. 15-44.

Montero Díaz, Mercedes: «Mujeres universitarias en España antes y después de la Guerra Civil: aspiraciones propias y ayudas ajenas (I9IO-I950)», en Folguera, Pilar; Pereira 
Castañares, Juan Carlos; García García, Carmen; Izquierdo Martín, Jesús; Pallol Trigueros, Rubén; Sánchez García, Raquel; Sanz Díaz, Carlos y Toboso Sánchez, Pilar (coords.): Pensar con la historia desde el siglo XXI: actas del XII Congreso de la Asociación de Historia Contemporánea, Madrid, Universidad Autónoma de Madrid, 2015, pp. I045-1064.

Morcillo Gomez, Aurora: «Sexo pensante, sexo cambiante: la educación media y superior de las españolas en los años cincuenta», Arenal: Revista de Historia de las Mujeres, I7, 2 (2010), pp. 299-318.

Muñoz Muñoz, Ana M. y Ballarín Domingo, Pilar (coords.): Mujeres y libros: homenaje a la profesora Dña. Isabel de Torres Ramírez, Granada, Editorial Universidad de Granada, 20IO, $218 \mathrm{pp}$.

Negrín Fajardo, Olegario: «La represión de maestras republicanas en la provincia de Las Palmas durante la guerra civil. Estudio de casos», en Sánchez de Madariaga, Elena (ed.): Las maestras de la República, Madrid, Los Libros de la Catarata, 20I2, pp. I66-183.

Núñez Gil, Marina y Rebollo Espinosa, María José: «“Anuncia, que algo queda”: la publicidad, un recurso didáctico para la historia de la educación de las mujeres en la España del siglo xx», en Espigado Tocino, M. Gloria; Fernández Gómez, Juan; Pascua, María José de la; Sánchez-Villanueva, Juan Luis y Vázquez Domínguez, Carmen (eds.): La Constitución de Cádiz: genealogía y desarrollo del sistema educativo liberal, Cádiz, Universidad de Cádiz, 2013, pp. 879-886.

Ofer, Inbal: «Teresa, ¿ revista para todas las mujeres?: Género, clase y espacios de la vida cotidiana en el discurso de la Sección Femenina (1960-1970)», Historia y Política: Ideas, Procesos y Movimientos Sociales, 37 (20I7), pp. I2I-I46.

Olhaberriague Ruiz de Aguirre, Concha d': «María de Maeztu y su gran misión pedagógica», Revista de Occidente, 4I3 (2015), pp. 29-43.

Palacio Lis, Irene: «Mujeres aleccionando a mujeres, discursos sobre la maternidad en el siglo XIX», Historia de la Educación: Revista Interuniversitaria, 26 (2007), pp. III-I42.

Palacio Lis, Irene: «Historia de la Educación de las mujeres. Cuestiones metodológicas», en vv. AA.: Historia de la Educación de las Mujeres, Murcia, Sociedad Española de Historia de la Educación, 2009, pp. 6I-88.

Palacio Lis, Irene: «Las mujeres como sujetos de adoctrinamiento: el ideal de la maternidad en España a finales del xix y comienzos del xx», en Vergara Ciordia, Javier; Sánchez Barea, Rafael Fermín y Comella Gutiérrez, Beatriz (coords.): Ideales de formación en la bistoria de la educación, Madrid, Dykinson, 20II, pp. 521-546.

Palomares Ibáñez, Jesús María: Mujeres universitarias: el Colegio Mayor "Santa María del Castillo» (1949-198I), Valladolid, Universidad de Valladolid, Servicio de Publicaciones e Intercambio Editorial, 20I0, I75 pp.

Palomares Ibáñez, Jesús María y Rodríguez Serrador, Sofía: El Colegio Mayor María de Molina (I93I-1975): por una educación universitaria integral, Valladolid, Ediciones Universidad de Valladolid, Instituto Universitario de Historia Simancas, 2013, 178 pp.

Pando Ballestero, María de la Paz: «La teorización sobre el alumnado femenino en la universidad franquista a la luz del caso de Salamanca», en Cuesta, Josefina; De Prado, María Luz y Rodríguez, Francisco J.: ¿ Mujeres sabias? Mujeres universitarias en España y América Latina, Limoges, Pulim (Presses Universitaires de Limoges), 2015, pp. 263-299.

Patrizi, Elisabetta: «La renovación tridentina y la educación espiritual de las mujeres en la experiencia de vida monacal femenina», Historia y Memoria de la Educación, 4 (2016), pp. $19-48$.

Peinado Rodríguez, Matilde: Enseñando a señoritas y sirvientas: formación femenina y clasismo en el franquismo, Madrid, Catarata, 20I2, I73 pp.

Peralta Ortiz, María Dolores: «Realidad educativa de la Institución Teresiana en los años veinte: crecimiento, consolidación y nuevas oportunidades», en RosiQue, Francisca (ed.): Historia de la Institución Teresiana (I9II-I936), Madrid, Sílex Universidad, 20I4, pp. 26I-287. 
Peralta Ortiz, María Dolores: «Orígenes y características de una residencia para universitarias en I9I4. La Residencia Teresiana de Madrid (I9I4-I936)», en CUESTA, Josefina; TuRRIón, María José y Merino, Rosa María (eds.): La Residencia de Señoritas y otras redes culturales femeninas, Salamanca, Ediciones Universidad de Salamanca-Madrid, Fundación Ortega y Gasset-Gregorio Marañón, 2015, pp. 313-338.

Pérez Marín, María Dolores: La Escuela de Paula Montal en sus documentos, Córdoba, Servicio de Publicaciones de la Universidad de Córdoba, 20I4, 374 pp.

Pérez Moreno, Heliodoro Manuel: La Sección Femenina de Huelva: misión, estructura e instituciones formativas, Sevilla, Hergué, 2008, 345 pp.

Pérez Sedeño, Eulalia y Canales Serrano, Antonio Francisco: «Educación superior e investigación científica: historia, sociología y epistemología», en Díaz, Capitolina y Dema, Sandra (eds.): Sociología y Género, Madrid, Tecnos, 2013, pp. 228-252.

Pérez Villanueva Tovar, Isabel: La Residencia de Estudiantes: 19I0-1936: grupo universitario y residencia de señoritas, Madrid, Acción Cultural Española-Consejo Superior de Investigaciones Científicas-Publicaciones de la Residencia de Estudiantes, 20II, 796 pp.

Pérez Villanueva Tovar, Isabel: «La Escuela del Hogar y Profesional de la Mujer y las enseñanzas domésticas (1911-1936)», Arenal: Revista de Historia de Mujeres, 22, 2 (2015a), pp. 313-345.

Pérez Villanueva Tovar, Isabel: «La Residencia de Señoritas. Mujeres y universidad», en Cuesta, Josefina; Turrión, María José y Merino, Rosa María (eds.): La Residencia de Señoritas y otras redes culturales femeninas, Salamanca, Ediciones Universidad de SalamancaMadrid, Fundación Ortega y Gasset-Gregorio Marañón, 2015b, pp. I3I-160.

Perrupato, Sebastián: «Innovación educativa y razón ilustrada: el lugar de la mujer en el pensamiento español del siglo XVIII", Fundación, I2 (2014-20I5), pp. 428-437.

Piñero SAmpayo, María Fernanda: La acción educativa de los colegios religiosos femeninos en la ciudad de Vigo: 1886-1962, tesis de doctorado, Universidade de Santiago de Compostela (2013).

Piñón, Pilar: «La universidad Internacional de Verano en Santander a través de sus profesoras y alumnas (1933-1936)», en Folguera, Pilar (coord.): Mujeres con voz. Voces desde el silencio. Una historia necesaria de la UIMP, Santander, UIMP, 20IO, pp. 203-23I.

Porto Ucha, Anxo Serafín y Vázquez Ramil, Raquel: «Diferencias de género en el sistema educativo liberal: las escuelas público-municipales de la ciudad de A Coruña en la época isabelina (I833-I868)», en Espigado Tocino, M. Gloria; Gómez Fernández, Juan; Pascua Sánchez, María José de la; Sánchez Villanueva, Juan Luis y Vázquez Domínguez, Carmen (eds.): La Constitución de Cádiz: genealogía y desarrollo del sistema educativo liberal, Cádiz, Universidad de Cádiz, 20I3, pp. 705-714.

Porto Ucha, Anxo Serafín y Vázquez Ramil, Raquel: «María Montessori en la Residencia de Señoritas de Madrid (1934): entre la vista social y el esbozo de proyecto pedagógico», en Hernández Díaz, José María (coord.): Influencias italianas en la educación española e iberoamericana, Salamanca, Ediciones Fahren House, 20I4, pp. 25I-262.

Porto Ucha, Anxo Serafín y Vázquez Ramil, Raquel: «Políticas de intercambio de estudiantes entre la residencia de señoritas de Madrid y los “colleges” estadounidenses de mujeres (1919-1936): similitudes y divergencias», en Folguera, Pilar; Pereira Castañares, Juan Carlos; García García, Carmen; Izquierdo Martín, Jesús; Pallol Trigueros, Rubén; Sánchez García, Raquel; Sanz Díaz, Carlos y Toboso Sánchez, Pilar (coords.): Pensar con la historia desde el siglo XXI: actas del XII Congreso de la Asociación de Historia Contemporánea, Madrid, Universidad Autónoma de Madrid, 20I5, pp. 987-I003.

Poveda SAnz, María: «¿Mujeres y profesionales de la segunda enseñanza?: El caso de instituto "Cardenal Cisneros" de Madrid durante la II República, Logros y retos», en VázQuez BERMÚDEZ, Isabel (coord.): Actas del III congreso universitario nacional "Investigación y género", Sevilla, Universidad de Sevilla, 20II, pp. I579-1589. 
Poveda Sanz, María: «Las universitarias que querían enseñar... en la universidad», en Folguera, Pilar; Pereira Castañares, Juan Carlos; García García, Carmen; Izquierdo Martín, Jesús; Pallol Trigueros, Rubén; Sánchez García, Raquel; Sanz Díaz, Carlos у Tовоso SÁnchez, Pilar (coords.): Pensar con la historia desde el siglo XXI: actas del XII Congreso de la Asociación de Historia Contemporánea, Madrid, Universidad Autónoma de Madrid, 2015, pp. I025-IO44.

Poy Castro, Raquel: «Mujeres y universitarias: historia de un desencuentro en la universidad española contemporánea», Cuestiones de Género: de la Igualdad y la Diferencia, 4 (2009), pp. 357-38I.

Poy Castro, Raquel: «Vencedoras y vencidas: las educadoras leonesas ante la Guerra Civil Española», Cuestiones de Género: de la Igualdad y la Diferencia, 6 (2011), pp. 239-263.

Pozo Andrés, María del Mar: «La construcción de la categoría “maestra republicana”: la tipología generacional como propuesta», en SÁnchez de MADARIAGA, Elena (ed.): Las maestras de la República, Madrid, Los Libros de la Catarata, 20I2, pp. 236-270.

Pozo Andrés, María del Mar del: Justa Freire o la pasión de educar. Biografía de una maestra atrapada en la historia de España (1896-1965), Barcelona, Octaedro, 2013, 346 pp.

Prado Herrera, María Luz de: «Tres universitarias excepcionales en la Salamanca de principios del siglo XX», en Cuesta, Josefina; De Prado, María Luz y Rodríguez, Francisco J.: ¿Mujeres sabias? Mujeres universitarias en España y América Latina, Limoges, Pulim (Presses Universitaires de Limoges), 2015, pp. I23-158.

Prieto Borrego, Lucía (ed.): Encuadramiento femenino, socialización y cultura en el franquismo, Málaga, Centro de Ediciones de la Diputación, 2010, 326 pp.

Puig Reixach, Miquel: «L'ensenyament de les nenes al segle xviII als corregiments de Girona i Vic: entre la caritat i la indústria popular», Annals del Patronat d'Estudis Històrics d'Olot i Comarca, 2I (20IO), pp. II-33.

Quesada Molina, María Teresa: La formación de maestras en las Academias Teresianas de Jaén, tesis de doctorado, Universidad de Sevilla (2016).

Rabazas Romero, Teresa: «Diferencias de género en los orígenes de la pedagogía española», en Espigado Tocino, M. Gloria; Fernández Gómez, Juan; Pascua, María José de la; Sánchez Villanueva, Juan Luis y Vázquez Domínguez, Carmen (eds.): La Constitución de Cádiz: genealogía y desarrollo del sistema educativo liberal, Cádiz, Universidad de Cádiz, 2013, pp. 727-738.

Rabazas Romero, Teresa y Ramos Zamora, Sara: «La recepción de la Escuela Nueva en algunos/as inspectores/as del franquismo becados por la J.A.E.», en SÁnchez Pascua, Felicidad; Alejo Montes, Francisco Javier; Calvo Población, Gaspar Félix; Lucero Fustes, Manuel; Oria Segura, María Rosa e Iglesias Verdegay, Enrique (coords.): Relaciones internacionales en la Historia de la Educación. La Junta para la Ampliación de Estudios e Investigaciones Cientificas (1907-2007), Madrid, Sociedad Española de Historia de la Educación, vol. I, 2007, pp. 219-232.

Rabazas Romero, Teresa y Ramos Zamora, Sara: «La figura della donna nelle letture scolastiche della Seconda Repubblica e del primo Franchismo (I936-I945)», en CAGnolati, Antonella (coord.): Madri Sociali, Percorsi di genere tra educazione, politica e filantropia, Milano, Anicia, 2011, pp. 215-231.

Rabazas Romero, Teresa y Villamor Manero, Patricia: «La feminización de la enseñanza y su escasa repercusión en los equipos directivos», en Educación, ciudadanía y convivencia. Diversidad y sentido social de la educación, Madrid, Sociedad Española de Pedagogía, 2008, pp. 1855 -1862.

Rabazas Romero, Teresa y Villamor Manero, Patricia: «Trayectoria profesional de las directoras en el sistema educativo español (1970-2006)», en Berruezo Albéniz, María Reyes y Conejero López, Susana (coord.): El largo camino hacia una educación inclusiva: 
UNA DÉCADA DE PUBLICACIONES SOBRE HISTORIA DE LA EDUCACIÓN

DE LAS MUJERES (2007-20I7)

CONSUELO FLECHA GARCÍA

la educación especial y social del siglo XIX a nuestros días, Pamplona-Iruñea, vol. 2, 2009, pp. 4I5-426.

Rabazas Romero, Teresa y Villamor Manero, Patricia: «Estilos de dirección diferenciados por género", Sembrando Ideas, 4 (2010), pp. 27-38.

Rabazas Romero, Teresa; Villamor Manero, Patricia; Egido Gálvez, Inmaculada y Prieto EgIDo, Miriam: «Género y dirección escolar: acceso, ejercicio y estilos de liderazgo», en Grañeras Pastrana, Montserrat y Gil Novoa, Natalia (coords.): Mujeres en cargos de representación del sistema educativo II, Madrid, Instituto de la Mujer-CNIIE, 2OI2, pp. II9-204.

Ramírez García, Antonia: «Factores de incidencia en el abandono de los estudios de magisterio en el primer tercio del siglo xx en las escuelas normales de Córdoba», Historia de la Educación. Revista Interuniversitaria, 3I (2012), pp. I89-208.

Ramos Zamora, Sara: «Un ejercicio de intervención de la memoria: la represión de las maestras de la Segunda República», en Sánchez de Madariaga, Elena (ed.): Las maestras de la República, Madrid, Los Libros de la Catarata, 2012, pp. I47-165.

Ramos Zamora, Sara: «Educadoras, maestras: depuradas por su profesión», en NAsH, M. (ed.): Represión, resistencia, memoria. Las mujeres bajo la dictadura franquista, Granada, Comares, 20I3, pp. 63-70.

Ramos Zamora, Sara: «Ciudadanas rurales y su formación durante el franquismo», en AGUADo, Ana y SAnfeliu, Luz (eds.): Caminos de democracia. Ciudadanías y culturas democráticas en el siglo XX, Granada, Comares, 20I4, pp. 243-262.

Ramos Zamora, Sara: «Iniciativas de educación no formal para las mujeres rurales (1939-1975)», en Ramos Zamora, Sara (ed.): Entre lo doméstico y lo público. Capacitación profesional de las mujeres rurales en España (1940-1977), Madrid, Biblioteca Nueva, 2016a, pp. 73-113.

Ramos Zamora, Sara: «Actuación profesional de las mujeres en el ámbito rural», en Ramos Zamora, Sara (ed.): Entre lo doméstico y lo público. Capacitación profesional de las mujeres rurales en España (1940-1977), Madrid, Biblioteca Nueva, 20I6b, pp. II5-I70.

Ramos Zamora, Sara: «Tradición y modernidad: espacios de poder de las mujeres en el mundo rural durante el franquismo", Innovación Educativa, 26 (20I6c), pp. IOI-II2.

Ramos, Sara y Colmenar, María del Carmen: «Mujeres rurales y capacitación profesional en el franquismo a través de la prensa femenina (1939-1959)», Educació i història: Revista d'bistòria de l'educació, 24 (2014), pp. I35-17I.

Ramos, Sara y Rabazas, Teresa: «Mujeres e instrucción rural en el desarrollismo español», Historia de la Educación: Revista Interuniversitaria, 26 (2007), pp. 22I-256.

Real Apolo, Carmelo: «Las Instructoras Diplomadas Rurales y la formación de la mujer en la provincia de Badajoz», Revista de Estudios Extremeños, 69, 2 (2013), pp. 1327-1348.

Rebollo Espinosa, María José: «Aprendiendo a ser mujer en la España del siglo xx: una mirada desde el Museo Pedagógico de la Facultad de Ciencias de la Educación de la Universidad de Sevilla», Cabás, I3 (20I5), pp. I5I-I59.

Rebollo Espinosa, María José y NúÑez Gil: Marina: «Tradicionales, rebeldes, precursoras: instrucción y educación de las mujeres españolas a través de la prensa femenina (I9001970)», Historia de la Educación: Revista Interuniversitaria, 26 (2007), pp. I8I-219.

Reig Ferrer, Ana María: El compromiso social de un político krausista: Rafael Albiñana y la Institución para la Enseñanza de la Mujer en Valencia, [s. 1.], 20I2, I60 pp.

Ribagorda Esteban, Álvaro: «La vida cultural en la Residencia de Señoritas en el Madrid de la Edad de Plata», en Cuesta, Josefina; Turrión, María José y Merino, Rosa María (eds.): La Residencia de Señoritas y otras redes culturales femeninas, Salamanca, Ediciones Universidad de Salamanca-Madrid, Fundación Ortega y Gasset-Gregorio Marañón, 20I5, pp. 16I-196.

Rico Gómez, María Luisa: «Mujer, enseñanza profesional y modernización en España (i88o1930)», Historia Contemporánea, 4I (2010), pp. 447-480.

Rico Gómez, María Luisa: «La mujer y las Escuelas de Artes y Oficios en la España de la Restauración», Cuadernos Kóre, 6 (2012), pp. 83-I13. 
Risueño Jurado, Virginia: «Mujeres docentes en las imágenes de los manuales escolares: España (190i-1940)», en Celada Perandones, Pablo (ed.): Arte y oficio de enseñar: dos siglos de perspectiva histórica, XVI Coloquio Nacional de Historia de la Educación, Soria, El Burgo de Osma, vol. 2, 2oII, pp. 487-496.

Rivera BalbOA, Blas: Historia de la educación primaria en Jódar en el siglo XIX. La incorporación de las mujeres a la escuela. El acceso a la enseñanza primaria como maestras y como alumnas, tesis de doctorado, Universidad de Jaén (20I2).

Robles SAnjuÁn, Victoria: «De cuerpos y deberes, el cuerpo como referente moral de la educación de las mujeres del siglo XIX», en Muñoz MuÑoz, Ana M.; Gregorio GiL, Carmen y SÁnchez Espinosa, Adelina (coords.): Cuerpos de mujeres: miradas, representaciones e identidades, Granada, Universidad de Granada, 2007a, pp. I09-I22.

Robles Sanjuán, Victoria: «Pensamiento educativo y cualificación profesional a través de algunas maestras pensionadas», en Sánchez Pascua, Felicidad; Alejo Montes, Francisco Javier; Calvo Población, Gaspar Félix; Lucero Fustes, Manuel; Oria Segura, María Rosa e Iglesias Verdegay, Enrique (coords.): Relaciones internacionales en la Historia de la Educación: Junta para la Ampliación de Estudios e Investigaciones Científicas (1907-2007), Madrid, Sociedad Española de Historia de la Educación, vol. I, 2007b, pp. 25I-260.

Robles SANJuÁn, Victoria: «Feminismo y memoria educativa: las trayectorias profesionales de maestras, directoras e inspectoras en el sistema educativo español, I970-200I», en JUAN, Víctor (coord.): Museos pedagógicos: la memoria recuperada, Huesca, Museo Pedagógico de Aragón, 2008, pp. I09-II5.

Robles SANJUÁn, Victoria: «La extraña relación entre la "incapacidad de” y la "sobrecapacidad para” en la literatura escolar para niñas y mujeres (siglos xIx y xx)», Feminismo/s, I3 (2009), pp. 69-84.

Robles SAnjuán, Victoria: «Cambios pedagógicos en la España de los setenta y ochenta: discursos teóricos y propuestas educativas desde el movimiento feminista», Annals del Patronat d'Estudis Històrics d'Olot i Comarca, 2I (20IOa), pp. 297-313.

Robles SAnjuán, Victoria: «Discursos y estrategias para un proyecto de escuela coeducativa en la transición española. Algunas fuentes para su estudio», Cabás, 3 (20Iob), pp. I-I3.

Robles Sanjuán, Victoria: «Educación generacional y franquismo: Discursos educativos y conflictos de vida», en Muñoz Muñoz, Ana M. y Ballarín Domingo, Pilar (coords.): Mujeres y libros: homenaje a la profesora Dña. Isabel de Torres Ramírez, Granada, Publs. Universidad de Granada, 2oroc, pp. I87-198.

Robles SANjuÁn, Victoria: «Paradojas para un pensamiento ilustrado sobre la igualdad. Mary Wollstonecraft y la educación femenina», en Espigado Tocino, M. Gloria; Gómez Fernández, Juan; Pascua Sánchez, María José de la; Sánchez Villanueva, Juan Luis y VázQuez Domínguez, Carmen (eds.): La Constitución de Cádiz: genealogía y desarrollo del sistema educativo liberal, Cádiz, Universidad de Cádiz, 20I3, pp. 59-72.

Robles SAnjuán, Victoria: «Dos siglos de conquistas por la igualdad: La educación de las mujeres en los siglos XIX y XX», Andalucía en la Historia, 49 (2015), pp. I4-I7.

Rodríguez CASTAÑo, Ana: La veterinaria en femenino: pioneras en España y evolución profesional en la comunidad de Madrid, tesis de doctorado, Universidad Complutense de Madrid (2016).

Rodríguez Hernández, Juan Pedro y Vázquez Risco, Elena: «La educación de la mujer», Medieval: Arqueología, Historia y Viajes sobre el Mundo, Barcelona, Año IX, 5I (20I4), pp. 38-45.

Rodríguez López, Carolina: "Las universitarias», en López-Ríos Moreno, Santiago y González CÁrceles, Juan Antonio (coords.): La Facultad de Filosofía y Letras de Madrid en la Segunda República: Arquitectura y Universidad durante los años 30, Madrid, Sociedad Estatal de Conmemoraciones Culturales-Ayuntamiento de Madrid-Fundación Cultural COAM-EA-Ediciones de Arquitectura, 2008, pp. 474-49I. 
Rodríguez López, Carolina: «Experiencias universitarias en torno a i9io. El centenario del acceso de la mujer a los estudios universitarios», Participación Educativa, I5 (2010), pp. 209-219.

Rodríguez López, Carolina: «Del pupitre a la tarima. Mujeres, ciencia y universidad en España en el primer tercio del siglo xx: líneas de trabajo y debates», en CAPEL Martínez, Rosa María (coord.): Presencia y visibilidad de las mujeres: recuperando historia, Madrid, Abada Editoriales, 2013, pp. 283-312.

Romero de Pablos, Ana: «Mujeres científicas en la dictadura de Franco. Trayectorias investigadoras de Piedad de la Cierva y María Aránzazu Vigón», Arenal: Revista de Historia de las Mujeres, 24, 2 (2017), pp. 319-348.

Rosique Navarro, Francisca y Peralta Ortiz, María Dolores: «La Institución Teresiana durante la Dictadura de Primo de Rivera. Una aproximación a su proyección educativa, social y pública», Hispania Sacra, 64, I29 (2012), pp. 345-377.

Rueda Andrades, Juan Diego: «La Escuela Normal del Magisterio en Sevilla de I93r a 1945: El intento republicano de implantar la coeducación», Cabás, 2 (2009), pp. I-26.

Ruiz-Berdún, María Dolores: «La primera enseñanza reglada de las matronas en España: el Real Colegio de Cirugía de San Carlos de Madrid», Llull: Revista de la Sociedad Española de Historia de las Ciencias y de las Técnicas, 36, 78 (2013), pp. 387-410.

SaAvedra Mitjans, Helena: «Mujeres universitarias en el distrito universitario de Barcelona en el Franquismo: una aproximación cuantitativa», en Folguera, Pilar; Pereira CastaÑares, Juan Carlos; García García, Carmen; Izquierdo Martín, Jesús; Pallol Trigueros, Rubén; Sánchez García, Raquel; Sanz Díaz, Carlos y Toboso Sánchez, Pilar (coords.): Pensar con la historia desde el siglo XXI: actas del XII Congreso de la Asociación de Historia Contemporánea, Madrid, Universidad Autónoma de Madrid, 2015, pp. 1065-1089.

SAAVEDRA Mitjans, Helena: Mujeres y universidad franquista, trayectorias vitales, académicas $y$ profesionales, tesis de doctorado, Universitat Autònoma de Barcelona (2016).

Salinas Catalá, Jesús: «Una aproximación a la historia de la escolarización de las gitanas y gitanos españoles (I. ${ }^{a}$ parte: siglos XV al XIX)», Cabás, I3 (20I5a), pp. 92-II2.

Salinas Catalá, Jesús: «Una aproximación a la historia de la escolarización de las gitanas y gitanos españoles (2. ${ }^{a}$ parte: siglos XX y XXI)», Cabás, I4 (20I5b), pp. 96-I26.

Samaniego Boneu, Mercedes: «La acción educadora en la Segunda República», en Rosique, Francisca (ed.): Historia de la Institución Teresiana (I9II-I936), Madrid, Sílex Universidad, 2014, pp. 289-312.

SAN Román, Sonsoles: "Contrastes entre identidades profesionales de la maestra española», TEMPORA. Revista de Sociología de la Educación, io (2007), pp. 59-86.

SÁnchez Blanco, Laura: La educación política y social de dos organizaciones femeninas en la Guerra Civil española: auxilio social y mujeres libres, tesis de doctorado, Universidad Pontificia de Salamanca (2013).

SÁnchez Blanco, Laura: «Mujeres Libres en la Guerra Civil española. La capacitación cultural y profesional en la región de Cataluña», Social and Education History, 6, 3 (2017), pp. 290-313.

Sánchez Blanco, Laura y Hernández Huerta, José Luis: «La educación femenina en el sistema educativo español (I857-2007)», El Futuro del Pasado, 3 (20I2), pp. 255-28I.

Sánchez de Madariaga, Elena (ed.): Las maestras de la República, Madrid, Los Libros de la Catarata, 20I2a, $270 \mathrm{pp}$.

SÁnchez de Madariaga, Elena: «Las maestras de la República en el recuerdo», en SÁnchez de Madariaga, Elena (ed.): Las maestras de la República, Madrid, Los Libros de la Catarata, 20I2b, pp. II-22.

Sánchez Morillas, Carmen: «La figura de la maestra rural en la Segunda República», Revista de Antropología Experimental, io especial (2010), pp. II9-I28.

Sánchez Morillas, Carmen María: María Josefa Segovia: una intelectual del siglo XX, tesis de doctorado, Universidad de Jaén (20II). 
SÁnchez Morillas, Carmen María: «Las maestras rurales», en SÁnchez de Madariaga, Elena (ed.): Las maestras de la República, Madrid, Los Libros de la Catarata, 20I2, pp. 9I-Io5.

SÁnchez Prieto, Ana Belén: «La educación de la mujer antes del año Iooo: ¿Es Dhuoda un caso único?, Educación XXI: Revista de la Facultad de Educación, I3, 2 (2010), pp. 69-94.

SÁnchez VIDAL, María Soledad: «La educación de la mujer en el contexto sociopolítico y educativo contemporáneo español», Historia Digital, I6, 28 (2016), pp. 53-85.

SANCHIDRIÁN Blanco, María del Carmen: «Estudios universitarios y ejercicio profesional de las mujeres en el franquismo», en Jiménez Fernández, Carmen y Pérez Serrano, María Gloria (coords.): Educación y género: el conocimiento invisible, Valencia, Ed. Tirant lo Blanch-UNED, 2008, pp. 217-248.

Sanchidrián Blanco, María del Carmen; Grana Gil, Isabel y Martín Zúñiga, Francisco: "Análisis y valoración de los expedientes de depuración del profesorado de Instituto de Segunda Enseñanza en el franquismo (1936-1942): resultados generales», Revista de Educación, 356 (2011), pp. 377-399.

SAncho Rodríguez, María Isabel y Cruz Rodríguez, María Alcázar: «Las escuelas primarias de Jaén. Siglo xx. II. Las mujeres de la provincia de Jaén en la primera enseñanza. Primer tercio del siglo xx», en Cabrera Espinosa, Manuel y López Cordero, Juan Antonio (eds.): VII Congreso virtual sobre Historia de las Mujeres, 20I5, pp. 745-8I8.

Seguí Marco, Juan José: «La docencia femenina en la Hispania romana: una infundada conjetura», Historia de la Educación: Revista Interuniversitaria, 34 (2015), pp. 191-205.

Segura Graíño, Cristina: «La educación de las mujeres en el tránsito de la Edad Media a la Modernidad», Historia de la Educación: Revista Interuniversitaria, 26 (2007), pp. 65-83.

Serrano Jerez, Elena y Nieto Galan, Agustí: Science for women in the Spanish enlightenment 1753-1808, Barcelona, Universitat Autònoma de Barcelona, 2014, 287 pp.

SeseÑa, Natacha: «Asociación Española de Mujeres Universitarias (I920-1990). Setenta años de labor seria y libre a favor de la mujer», en González Ruiz, Pilar; Martínez Ten, Carmen y Gutiérrez López, Purificación (coords.): El movimiento feminista en España en los años 70, Madrid, Cátedra, 2009, pp. 377-384.

Sixto Barcia, Ana María: «La educación femenina en Galicia a finales del Antiguo Régimen», Innovación Educativa, 26 (2016), pp. 13-27.

Socías MuÑoz, Estela: «Las Maestras Parvularias a Inicios del Siglo xx en Chile», Cabás, II (20I4), pp. I6-24.

Sonlleva Velasco, Miriam: «La escuela rural (1939-1951) y su contexto. Entrevista a una alumna segoviana», Cabás, I7 (2017), pp. I50-167.

Soto Vázquez, José: «Las escuelas de niñas en Los Santos de Maimona (I857-1910)», Revista de Estudios Extremeños, 66, I (2010), pp. 9I-I35.

Sureda García, Bernat; Motilla Salas, Xavier y Comas Rubí, Francesca: «La revista Feminal: fotografía y visualización de la aportación femenina a la renovación educativa en Cataluña 1907-1917», Historia de la Educación: Revista Interuniversitaria, 33 (2014), pp. 215-230.

Torrebadella Flix, Xavier: «La educación física y la actividad gimnástico-deportiva de las mujeres a partir de la bibliografía especializada del siglo XIX», Arenal: Revista de Historia de las Mujeres, I8, I (20II), pp. I47-179.

Torrebadella Flix, Xavier: «Las primeras profesoras de gimnástica en España. Profesión liberal y coartada durante el siglo XIX», RICYDE. Revista Internacional de Ciencias del Deporte, I2, 46 (2016), pp. 423-444.

Torrebadella Flix, Xavier: «La historia de la educación física escolar en España. Una revisión bibliográfica transversal para incitar a una historia social y crítica de la educación física», Espacio, Tiempo y Educación, 4, I (2017), pp. I-4I.

Torres Alé, María del Mar de: El modelo educativo de Luisa de Marillac, tesis de doctorado, Universidad de Cádiz (20I7). 
Torres López, Matilde: La mujer en la docencia y la práctica artística en Andalucía durante el siglo XIX, tesis de doctorado, Universidad de Málaga (2007).

Torres López, Matilde: Artistas andaluzas: docencia y creación artística en el siglo XIX, Málaga, Servicio de Publicaciones, Centro de Ediciones de la Diputación de Málaga (CEDma), 20IO, $366 \mathrm{pp}$.

Turrión García, María José: «Fuentes para un estudio de las mujeres universitarias en el Centro documental de la memoria histórica (represión, exilio y dictadura)», en Cuesta, Josefina; De Prado, María Luz y Rodríguez, Francisco J.: ¿ Mujeres sabias? Mujeres universitarias en España y América Latina, Limoges, Pulim (Presses Universitaires de Limoges), 2015, pp. 185-223.

Vaamonde Gamo, Marta y Nubiola, Jaime: «El legado feminista de John Dewey», Espacio, Tiempo y Educación, 3, 2 (2016), pp. 28I-300.

Val Valdivieso, María Isabel del: «La educación en la corte de la Reina Católica», Miscelánea Comillas: Revista de Ciencias Humanas y Sociales, 69, I34 (201I), pp. 255-273.

Val Valdivieso, María Isabel del y Martínez Quinteiro, Esther (eds.): Comiendo del fruto probibido: mujeres, ciencia y creación a través de la Historia, Barcelona, Icaria, 2015, 192 pp.

Valbuena, Cecilia: «La obra de Elisa López Velasco: la enseñanza del dibujo orientada por la escuela activa», en Padrós, Núria; Collelldemont, Eulàlia y Soler, Joan (eds.): Arte, literatura y educación, Vic, Universitat de Vic-Universitat Central de Catalunya, 2, 20I5, pp. 26I-273.

Vales-Villamarín, Helena y Reder Gadow, Marion: «Política Educativa Ilustrada: Una visión comparada de la fundación de Escuelas de Primeras Letras (siglo XviII)», Americanía: Revista de Estudios Latinoamericanos de la Universidad Pablo de Olavide de Sevilla, I (2015), pp. 59-94.

Valle López, Ángela de: «Una propuesta educativa en las primeras décadas del siglo xx», en Rosique, Francisca (ed.): Historia de la Institución Teresiana (I9II-I936), Madrid, Sílex Universidad, 20I4, pp. 20I-259.

Vázquez Domínguez, M. Carmen: La historia de las escuelas femeninas de Cádiz en el siglo $X I X$, tesis de doctorado, Universidad de Cádiz (20I6).

VÁzQUEz RAmil, Raquel: Mujeres y educación en la España contemporánea: la Institución Libre de Enseñanza y la Residencia de Señoritas de Madrid, Madrid, Akal, 20I2a, 496 pp.

VÁzquez Ramil, Raquel: «Mulleres galegas na Residencia de Señoritas de Madrid, "cando van, van como rosas...”", Sarmiento: Anuario Galego de Historia da Educación, I6 (2012b), pp. IOI-I2O.

VÁzQuez Ramil, Raquel: «La educación de las mujeres en España (1900-1939). La Institución Libre de Enseñanza y la Residencia de Señoritas de Madrid», en Hernández Huerta, José Luis; Quintano Nieto, Judith y Ortega Gaite, Sonia (coords.): Utopía y Educación. Ensayos y Estudios, Salamanca, Ediciones FahrenHouse, 20I4, pp. I3I-I5I.

VÁzQuez RAmil, Raquel: «Entre el suelo y el cielo: la educación de la mujer durante la Segunda República (193I-1936)», en González Penín, Anabel; López Díaz, Ana Jesús y Aguayo Lorenzo, Eva (ed.): Trazos de xénero no século XXI, Vigo, Universidade de Vigo, 20I5a, pp. 269-277.

VÁzQuez Ramil, Raquel: «La Residencia de Señoritas de Madrid durante la Segunda República: entre la alta cultura y el brillo social», Espacio, Tiempo y Educación, 2, I (2015b), pp. 323-346.

VÁzquez Ramil, Raquel: «Francisco Giner de los Ríos y la educación de la mujer: consideraciones teóricas y perspectiva práctica», INDIVISA. Boletín de Estudios e Investigación, I6, (2016), pp. 65-82.

Verdugo Martí, Vicenta: «Pioneras universitarias: las primeras mujeres de la Universidad de Valencia», en Espigado Tocino, M. Gloria; Fernández Gómez, Juan; Pascua, María José de la; Sánchez Villanueva, Juan Luis y Vázquez Domínguez, Carmen (eds.): La 
Constitución de Cádiz: genealogía y desarrollo del sistema educativo liberal, Cádiz, Universidad de Cádiz, 2013, pp. 785-798.

Viejo SÁnchez, María Luisa: «El pensamiento de Lluis Vives sobre la educación de la mujer cristiana a la luz de la teología católica actual», en Coronel Ramos, Marco Antonio: Juan Luis Vives: el humanista y su entorno, Valencia, Institució Alfons el Magnánim, 2017, pp. 377-4I2.

Villa Fernández, Nuria: «Tres mujeres liberales en la obra de un hombre: Aportaciones de Pilar Pascual Sanjuán, Matilde del Real Mijares y María Carbonell y Sánchez», en EsPIGAdo Tocino, M. Gloria; Fernández Gómez, Juan; Pascua, María José de la; Sánchez Villanueva, Juan Luis y Vázquez Domínguez, Carmen (eds.): La Constitución de Cádiz: genealogía y desarrollo del sistema educativo liberal, Cádiz, Universidad de Cádiz, 2013, pp. I6I-I74.

VV. AA.: Ferrol en femenino II: primeros pasos na educación das mulleres en Ferrol do século XVIII ao $\mathrm{XX}$, Ferrol, Concello, 20I0, $47 \mathrm{pp}$.

Wollstonecraft, Mary: La educación de las hijas, prólogo de Amelia Valcárcel Bernaldo de Quirós, traducción, Cristina López González, Santander, El Desvelo, 20ı, I0s pp. 